\title{
MHD natural convection and entropy generation in a grooved enclosure filled with nanofluid using two-component non-homogeneous model
}

\author{
Mohammad Mokaddes $\mathrm{Ali}^{1} \cdot$ Rowsanara Akhter ${ }^{2} \cdot$ Md. Abdul Alim $^{3}$
}

Received: 20 January 2020 / Accepted: 22 February 2020 / Published online: 6 March 2020

(c) Springer Nature Switzerland AG 2020

\begin{abstract}
In this paper, a computational study of natural convection in a grooved enclosure filled with water-based nanofluid in the presence of external magnetic field is numerically investigated. Two-component non-homogeneous model is introduced to develop the governing partial differential equations. Galerkin finite element method is used to solve the governing equations. The computation is carried out for a wide range of governing parameters such as Rayleigh number $\left(10^{3} \leq \mathrm{Ra} \leq 10^{6}\right)$, magnetic field parameter $(10 \leq \mathrm{Ha} \leq 100)$ and volume fraction of nanoparticles $(0 \% \leq \phi \leq 5 \%)$ with fixed values of remaining parameters. A detailed parametric analysis is performed to show the effects of physical parameters on the fluid flow and temperature distributions within the enclosure via streamlines, isotherms, isoconcentrations, midsectional velocities, average Nusselt number and temperature, respectively. In addition, the entropy generation and Bejan number are also computed and discussed elaborately. The results of the current study are compared to those of previous numerical and experimental studies and found to be in rational agreements. The results ascertain that the average Nusselt number and entropy generation increase with rising Rayleigh number and nanoparticle volume fraction, whereas they decrease with increasing magnetic field strength. Moreover, it is found that the appropriate combination of governing parameters can maximize the heat transfer rate and minimize the entropy generation as well.
\end{abstract}

Keywords Magnetic field · Natural convection · Entropy generation · Nanofluids · Non-homogeneous model · Finite element method

\section{List of symbols}

$c_{p} \quad$ Specific heat $\left(\mathrm{J} \mathrm{kg}^{-1} \mathrm{~K}^{-1}\right)$

$D_{\mathrm{B}} \quad$ Brownian diffusion coefficient $\left(\mathrm{kg} \mathrm{m}^{-1} \mathrm{~s}^{-1}\right)$

$D_{\mathrm{B} 0} \quad$ Reference Brownian diffusion coefficient $\left(\mathrm{kg} \mathrm{m}^{-1} \mathrm{~s}^{-1}\right)$

$D_{\mathrm{T}} \quad$ Thermophoretic diffusivity coefficient $\left(\mathrm{kg} \mathrm{m}^{-1} \mathrm{~s}^{-1}\right)$

$D_{T 0} \quad$ Reference thermophoretic diffusion coefficient $\left(\mathrm{kg} \mathrm{m}^{-1} \mathrm{~s}^{-1}\right)$

$d_{\mathrm{s}} \quad$ diameter of nanoparticle $(\mathrm{nm})$

$g$ Gravitational acceleration $\left(\mathrm{ms}^{-2}\right)$

$L \quad$ Length of the enclosure $(\mathrm{m})$

Le Lewis number $k \quad$ Thermal conductivity $\left(\mathrm{W} \mathrm{m}^{-1} \mathrm{~K}^{-1}\right)$

$K_{\mathrm{B}} \quad$ Boltzmann's constant $\left(\mathrm{J} \mathrm{K}^{-1}\right)$

$N_{\text {BT }} \quad$ Ratio of Brownian to thermophoretic diffusivity

$\operatorname{Pr} \quad$ Prandtl number $\operatorname{Pr}=v_{\mathrm{f}} / \alpha_{\mathrm{f}}$

$p \quad$ Dimensional pressure $\left(\mathrm{N} \mathrm{m}^{-2}\right)$

$P \quad$ Dimensionless pressure

$q_{\mathrm{w}} \quad$ Heat flux $\left(\mathrm{W} \mathrm{m}^{-2}\right)$

Ra Rayleigh number $g \beta_{\mathrm{f}}\left(T_{\mathrm{h}}-T_{\mathrm{c}}\right) L^{3} / v_{\mathrm{f}} \alpha_{\mathrm{f}}$

Sc Schmidt number

$T \quad$ Dimensional temperature $(\mathrm{K})$

$u, v$ Dimensional velocity components $\left(\mathrm{ms}^{-1}\right)$

$U, V$ Dimensionless velocity components

\footnotetext{
$\triangle$ Mohammad Mokaddes Ali, mmali309@gmail.com | ${ }^{1}$ Department of Mathematics, Mawlana Bhashani Science and Technology University, Tangail 1902, Bangladesh. ${ }^{2}$ Department of Electrical and Electronic Engineering, International University of Scholars, Dhaka, Bangladesh. ${ }^{3}$ Department of Mathematics, Bangladesh University of Engineering and Technology, Dhaka 1000, Bangladesh.
} 


\section{$x, y \quad$ Dimensional coordinates $(\mathrm{m})$ \\ $X, Y$ Dimensionless coordinates}

\section{Greek symbols}

$\alpha \quad$ Fluid thermal diffusivity $\left(\mathrm{m}^{2} \mathrm{~s}^{-1}\right)$

$\beta \quad$ Thermal expansion coefficient $\left(\mathrm{K}^{-1}\right)$

$\phi \quad$ Volume fraction of nanoparticles

$\phi^{*} \quad$ Normalized volume fraction

$\theta \quad$ Dimensionless temperature $\theta=\left(T-T_{\mathrm{c}}\right) /\left(T_{\mathrm{h}}-T_{\mathrm{c}}\right)$

$\mu \quad$ Dynamic viscosity $\left(\mathrm{N} \mathrm{sm}^{-2}\right)$

$v \quad$ Kinematic viscosity $\left(\mathrm{m}^{2} \mathrm{~s}^{-1}\right)$

$\rho \quad$ Density $\left(\mathrm{kg} \mathrm{m}^{-3}\right)$

\section{Subscripts}

ave Average

f $\quad$ Fluid

s Nanoparticle

h Hot

c Cold

nf Nanofluid

HT Heat transfer

FF Fluid friction

MF Magnetic field

\section{Introduction}

Buoyancy-driven natural convection in a closed enclosure has received a considerable attention from the researchers due to its numerous applications in industrial and engineering fields such as heat exchangers, cooling of electronic devices, heating and cooling systems in building, solar technologies, aeronautics, nuclear reactors, petrochemical industries and geophysical fluid mechanics. Most of the engineering processes generate high temperature. Accordingly, the efficiency of thermal performance depends on the development of heat transfer mechanisms. Several techniques have been used to enhance the heat transfer performance in thermal engineering. Recently, nanofluids, a colloidal mixture of nanoparticles into base fluid (such as water, oil and ethylene glycol), have been used to improve the efficiency of heat transfer mechanisms according to Choi [1]. As heat transfer augmentation is an indispensable issue in conservation of energy, natural convection in nanofluid-filled enclosure plays a vital role in thermal engineering. In this context, a number of numerical and experimental studies have been conducted by many investigators. Among the initial endeavors of heat transfer augmentation using nanofluids, one study can be mentioned which was conducted by Khanafer et al. [2]. In their investigation, they numerically simulated the problem of heat transfer characteristics of nanofluids in a two-dimensional enclosure and reported that heat transfer rate increases to a large extent with the suspended nanoparticles at any value of Grashof number. Later on, this model was implemented by Jou and Tzeng [3] to analyze a similar study in rectangular enclosures filled with nanofluids. Their results explored that heat transfer coefficient is critical in nanofluids compared to pure fluids and increases with increasing Rayleigh number. After that, Tiwari and Das [4] developed a model to investigate the heat transfer properties of nanofluids in a two-sided lid-driven square cavity. Their results showed that suspended nanoparticles increase the heat transfer capability of base fluid which becomes more pronounced with rising solid volume fraction. It was also noted that fluid flow and heat transfer inside the cavity were affected for varying Richardson numbers and also the directions of moving walls. Kakac and Pramuanjaroenkij [5] reviewed the heat transfer development in nanofluids and summarized that nanofluids significantly improve the heat transfer capacity of thermal processes. They also recommended that more experimental and theoretical results are needed for better understanding of heat transfer mechanisms in nanofluids. The effect of nanoparticle volume fraction on natural convection flow in a cavity was experimentally investigated by Ghodsinezhad et al. [6]. They concluded that increasing concentration of nanoparticles could enhance natural convection heat transfer coefficient. After that, the effect of different nanoparticles and cavity aspect ratio on natural convection was numerically investigated by Goodarzi et al. [7], and they confirmed that the heat transfer mechanism strongly depends on the size of the cavity as well as different nanoparticles. Izadi et al. [8] utilized finite volume technique to numerically investigate the effect of nanoparticle concentration and inclination angle on mixed convection in an inclined square cavity with top moving wall. Their results indicated that the average Nusselt number decreases and increases, respectively, at the heated and cooled walls with increasing nanoparticle concentration. Later on, thermal non-equilibrium model was implemented by lzadi et al. [9] to numerically analyze natural convection in a micropolar nanofluid within a porous cavity. They recommended that heat transfer rate in porous medium increases with the reduction in thermal resistance of fluid domain with increasing thermal conductivity ratio. Sabour et al. [10] theoretically studied the natural convection flow of nanofluid in a square cavity. Their results showed the enhancement of heat transfer because nanofluid increases with Rayleigh number. They also observed the efficiency of using nanofluid affected by the type of nanoparticles as well as base fluid. Roy [11] implemented the finite difference technique to perform a numerical study of natural convection in a nanofluid-filled square enclosure having different inner geometries. He observed that Nusselt number linearly increases with the increase in nanoparticle volume fraction and exponentially 
increases for higher Rayleigh number. He also noted that increasing rate of heat transfer coefficient is affected by the shape of different inner geometries. Bondarenko et al. [12] developed natural convection cooling system by using heat-generating source and heat-conducting element at different locations on the bottom wall of a square cavity, and they found that the cooling efficiency due to addition of nanoparticles in base fluid depends on the location of the heat source. Buongiorno [13] developed a non-homogeneous equilibrium model by incorporating slip mechanisms, especially the Brownian diffusion and thermophoresis effects to progress the applications of nanofluids. Recently, a number of investigations have been performed using transport equations modeled by Buongiorno. Elshehabey and Ahmed [14] performed a numerical study of mixed convection in a lid-driven cavity by using Buongiorno's nanofluid model. Their results indicated that fluid flow declines due to the presence of inclined magnetic field and is dominated by the lid wall at highest values of buoyancy ratio. Noghrehabadi et al. [15] investigated the natural convection flow of nanofluid in a square cavity in the presence of heat source and sink. They pointed out that heat transfer rate enhances with an increase in Rayleigh number and concentration of nanoparticles in the presence of thermophoresis and Brownian effects. Motlagh and Soltanipour [16] considered nonhomogeneous two-phase Buongiorno's model to analyze nanoparticles distribution and heat transfer characteristics of nanofluid for natural convection in a tilted square enclosure. They found that heat transfer rate is optimum at higher Rayleigh number and nanoparticle volume fraction, and the distribution of nanoparticles remains almost uniform at high Rayleigh number for all inclination angles.

On the other hand, the study of electrically conducting fluid in the presence of magnetic field effect has significant applications in industrial and engineering fields such as crystal growth in liquids, cooling of microelectronic devices and nuclear reactors. Bourantas and Loukopoulos [17] utilized meshless point collocation with velocity correction method to simulate the transient natural convection flow of micropolar nanofluid in an inclined square cavity under the influence of magnetic field. Their results showed that the flow and temperature were affected significantly by the strength and orientation of magnetic field. Kasaeipoor et al. [18] analyzed the effects of magnetic field on mixed convection flow of $\mathrm{Cu}$-water nanofluid in a T-shaped cavity and suggested that augmentation of heat transfer rate with increasing volume fraction depends on a certain range of Reynolds number and Hartmann number. Job and Gunakala [19] investigated numerically the effect of viscous and joule dissipation on two-dimensional unsteady buoyancy-driven flow of alumina-water and SWCNT-water nanofluids in a wavy trapezoidal cavity in the presence of magnetic field. They reported that the flow circulation reduces and heat transfer rate increases for higher amplitude of the wavy bottom wall and opposite trend is also observed with an increase in time. Rahman et al. [20] considered the Buongiorno's non-homogeneous mathematical model to analyze free convection flow in an $\mathrm{Al}_{2} \mathrm{O}_{3}$-water nanofluid-filled isosceles triangular cavity in the presence of inclined magnetic field. Their results highlighted that the heat transfer rate decreases with increasing values of strength and inclination angle of magnetic field. They also noted the flow and thermal fields affected by the variable thermal boundary conditions studied. Ahrar and Djavareshkian [21] used lattice Boltzmann method to investigate the effects of volume fraction and magnetic field on flow and heat transfer in Cu-water nanofluid-filled cavity and revealed that the influence of nanoparticles on the flow and heat transfer strongly depends on Rayleigh and Hartmann numbers. M'hamed et al. [22] accomplished a brief review on the effects of external magnetic field on nanofluids and suggested a guideline for future research on the properties of magnetic fluids. Ali et al. [23] implemented finite element method to investigate MHD natural convection flow in a differentially heated hexagonal enclosure. Dixit and Pattamatta [24] conducted an experimental study of the influence of magnetic field on natural convection in a differentially heated cubical cavity. They demonstrated that the heat transfer rate turns down due to the magnetic field effects. It was also found that deterioration in heat transfer affects significantly with the direction of magnetic field, and the type as well as volume fraction of nanoparticles. Later on, dual reciprocity boundary element method (DRBEM) was introduced by Alsoy-Akgün [25] to simulate unsteady natural convection in $\mathrm{Al}_{2} \mathrm{O}_{3}$-water nanofluidfilled square cavity under the effect of uniform magnetic field and observed that the effect of magnetic field on the heat transfer performance and temperature profiles depends on buoyancy force due to Rayleigh number. They also noticed the effect of nanoparticle concentration on the fluid behaviors related to the effect of magnetic field parameter. The problem of natural convection in hybrid nanofluid-filled porous cavity subjected to a variable magnetic field was numerically investigated by Izadi et al. [26]. They suggested that heat transfer rate significantly increases and decreases with increasing porosity coefficient and Hartmann number, respectively. In addition, small change occurred in streamlines with an increase in volume fraction of nanoparticles.

Moreover, the thermodynamic efficiency in engineering and industrial applications such as heat exchangers, turbomachineries, cooling of electronics, porous media and combustion depends on its irreversibility magnitude during a heat transfer process, named as entropy 
generation. In this context, several numerical studies have been accomplished on entropy generation of convective flow problems. Bejan [27] developed a model for estimating and minimizing the irreversibility due to heat transfer configurations. Bouchoucha and Bessaih [28] conducted a numerical investigation of natural convection heat transfer and entropy generation in a square cavity filled with nanofluid. They showed the average Nusselt number increases with volume fraction of nanoparticles and Rayleigh number. Moreover, maximum total entropy generation was also found for different concentrations of nanoparticles at lower Rayleigh number. Mejri et al. [29] utilized lattice Boltzmann method (LBM) to examine the effects of magnetic field on laminar natural convection and entropy generation in a nanofluid-filled square cavity with sinusoidal heated side walls and reported that heat transfer rate and entropy generation, respectively, increase and decrease with increasing volume fraction of nanoparticles at critical values of Rayleigh and Hartmann numbers. Meshram et al. [30] studied numerically the influence of inclination angle of square cavity on natural convection and entropy generation. Their results highlighted the variation of Nusselt number and entropy generation due to inclination angle and became significant for higher values of Rayleigh number and Darcy number. Abbaszadeh et al. [31] considered slip velocity and temperature jump boundary conditions to investigate the effect of magnetic field on flow field, heat transfer and entropy generation of nanofluid through a microchannel. They observed the heat transfer rate and total irreversibility are increasing functions of Reynolds number, Hartmann number, volume fraction, and minimum entropy generation with higher Knudsen number. Mehmood et al. [32] numerically investigated the mixed convection and entropy generation in a lid-driven square cavity including heated square obstacle under the influence of magnetic field and found that heat transfer rate and entropy generation were influenced significantly with the governing parameters and moving wall. Hussain et al. [33] numerically analyzed the entropy generation for magnetohydrodynamic mixed convection in a hybrid nanofluid-filled horizontal channel containing an adiabatic blockage and found that average Nusselt number and entropy generation were affected with the variation in governing parameters. Alnajem et al. [34] presented a numerical study of entropy generation and heat transfer of nanofluid for natural convection in an isothermally heated cavity having a solid cylinder. Their results showed the heat transfer rate is an increasing function of Rayleigh number and nanoparticle volume fraction. They also observed that average Bejan number decreases with the increase in Rayleigh number, while fluid friction irreversibility was dominant.
Furthermore, the efficiency of thermal equipment can also be improved by appropriate geometrical modifications with additional surface area such as fins, grooves, corrugates and baffles. Accordingly, the limitation of lower heat transfer rate for simple geometrical model inspired us to develop a new geometrical model with square grooves to enhance heat transfer rate. In this regard, several studies have been conducted for different configurations to examine the flow and heat transfer behaviors. The thermal performance for a grooved heated pipe filled with nanofluids and hybrid nanofluids was experimentally studied by Han and Rhi [35], and they observed that thermal resistance is high with increasing nanoparticle concentration, whereas hybrid nanofluids make the system deteriorate in terms of thermal resistance. Sharma et al. [36] studied the mixed convection in a grooved channel in the presence of adiabatic baffle and concluded that heat transfer rate increases within the mixed convection regime due to the presence of a baffle. Kumar et al. [37] performed an experimental study on turbulent free convection in a cavity having smooth or grooved bottom surface in the presence of heat flux, and they highlighted that temperature distributions fluctuated remarkably for grooved surface than smooth. Job and Gunakala [38] carried out a numerical study on mixed convective flow of nanofluids in a grooved channel including solid cylinders in the presence of magnetic field effect. Their results indicated that flow and thermal fields were affected by the different groove geometries, cylinder radius and other relevant parameters. The effect of magnetic field on natural convection of nanofluid in a grooved enclosure with different thermal conditions was numerically analyzed by Ali et al. [39]. They found that flow and thermal fields were affected significantly due to the various thermal conditions. It was also noted that the heat transfer rate increases with the increase in Rayleigh number and solid volume fraction of nanoparticles.

From the open literature review, it is evident that there is no study on natural convection and entropy generation in a grooved enclosure filled with nanofluid using Buongiorno's nanofluid model. It is important to note that Buongiorno's nanofluid model based on Brownian diffusion and thermophoresis slip mechanisms causes relative velocity between nanoparticles and fluid. In addition, magnetic field can be used to control the fluid flow and heat transfer rate. The purpose of this study is to numerically examine the fluid flow, temperature and particles distributions as well as entropy generation for the effect of magnetic field on natural convection flow of nanofluid inside a grooved enclosure using Buongiorno's nanofluid model. The computed results are presented in terms of streamlines, temperature contours (isotherms), particle distribution contours (isoconcentrations), average Nusselt number, mid-sectional velocities, entropy generations and 
average Bejan number for a range of pertinent parameters and discussed from physical point of view. The prediction and also findings of this study can be a useful guide in designing of thermal equipments such as heat exchangers, electronics cooling equipments and biomedical equipments where high temperature and fluid flow need to be controlled.

\section{Physical model}

The physical model of the present study is shown in Fig. 1. The bottom horizontal walls of the enclosure are maintained isothermal high temperature $T_{h}$, while the grooved and vertical walls are at low temperature $T_{\mathrm{c}}$ and the remaining walls are set as adiabatic. The concentration at the bottom walls and grooved as well as vertical walls is, respectively, maintained by $C_{\mathrm{h}}$ and $C_{\mathrm{c}}$ where $C_{\mathrm{h}}>C_{\mathrm{c}}$. The working fluid inside the enclosure is assumed as waterbased nanofluid containing copper oxide nanoparticles, and having no chemical reactions [13] whose initial temperature is considered as $T_{c} \cdot \ln$ addition, it is assumed that both the fluid phase and nanoparticles are in a thermal equilibrium state. The thermo-physical properties of the considered nanoparticles and base fluid are given in Table 1.

\section{Mathematical analysis}

The governing equations describing the present flow model for two-dimensional laminar natural convection in a grooved enclosure can be written in dimensional form as $([13,15,16,32])$ :

$\frac{\partial u}{\partial x}+\frac{\partial v}{\partial y}=0$

$\rho_{\mathrm{nf}}\left(u \frac{\partial u}{\partial x}+v \frac{\partial u}{\partial y}\right)=-\frac{\partial p}{\partial x}+\mu_{\mathrm{nf}}\left(\frac{\partial^{2} u}{\partial x^{2}}+\frac{\partial^{2} u}{\partial y^{2}}\right)$
Table 1 Thermo-physical properties of the base fluid and copper oxide [31]

\begin{tabular}{lll}
\hline Physical properties & Base fluid & Copper oxide (CuO) \\
\hline$C_{p}(\mathrm{~J} / \mathrm{kg} \mathrm{K})$ & 4179 & 540 \\
$\rho\left(\mathrm{kg} / \mathrm{m}^{3}\right)$ & 997.1 & 6500 \\
$k(W / \mathrm{mK})$ & 0.613 & 18 \\
$\beta(1 / \mathrm{K})$ & $2.1 \times 10^{-4}$ & $0.085 \times 10^{-4}$ \\
$\sigma(\Omega \mathrm{m})^{-1}$ & 0.05 & $10^{-10}$ \\
\hline
\end{tabular}

$\begin{aligned} \rho_{\mathrm{nf}}\left(u \frac{\partial v}{\partial x}+v \frac{\partial v}{\partial y}\right)= & -\frac{\partial p}{\partial y}+\mu_{\mathrm{nf}}\left(\frac{\partial^{2} v}{\partial x^{2}}+\frac{\partial^{2} v}{\partial y^{2}}\right) \\ & +g \beta_{\mathrm{nf}} \rho_{\mathrm{nf}}\left(T-T_{\mathrm{c}}\right)-\sigma_{\mathrm{nf}} B_{0}^{2} v\end{aligned}$

$$
\begin{aligned}
& \left(\rho C_{p}\right)_{\mathrm{nf}}\left(u \frac{\partial T}{\partial x}+v \frac{\partial T}{\partial y}\right)=k_{\mathrm{nf}}\left(\frac{\partial^{2} T}{\partial x^{2}}+\frac{\partial^{2} T}{\partial y^{2}}\right) \\
& +\left(\rho c_{p}\right)_{\mathrm{s}} D_{\mathrm{B}}^{*}\left(\frac{\partial \phi^{*}}{\partial x} \frac{\partial T}{\partial x}+\frac{\partial C}{\partial y} \frac{\partial \phi^{*}}{\partial y}\right) \\
& +\left(\rho c_{p}\right)_{\mathrm{s}} \frac{D_{T}^{*}}{T_{\mathrm{c}}}\left(\left(\frac{\partial T}{\partial x}\right)^{2}+\left(\frac{\partial T}{\partial y}\right)^{2}\right)+\sigma_{\mathrm{nf}} B_{0}^{2} v^{2}
\end{aligned}
$$

$$
\begin{aligned}
\rho_{\mathrm{s}}\left(u \frac{\partial \phi^{*}}{\partial x}+v \frac{\partial \phi^{*}}{\partial y}\right)= & \rho_{\mathrm{s}} D_{\mathrm{B}}^{*}\left(\frac{\partial^{2} \phi^{*}}{\partial x^{2}}+\frac{\partial^{2} \phi^{*}}{\partial y^{2}}\right) \\
& +\rho_{\mathrm{s}} \frac{D_{\mathrm{T}}^{*}}{T_{\mathrm{c}}}\left(\frac{\partial^{2} T}{\partial x^{2}}+\frac{\partial^{2} T}{\partial y^{2}}\right) .
\end{aligned}
$$

Here, the properties of nanofluid can be defined as follows ([39-45]):

$\rho_{\mathrm{nf}}=(1-\phi) \rho_{\mathrm{f}}+\phi \rho_{\mathrm{s}}$

$\beta_{\mathrm{nf}}=(1-\phi) \beta_{\mathrm{f}}+\phi \beta_{\mathrm{s}}$

$\left(\rho c_{p}\right)_{\mathrm{nf}}=(1-\phi)\left(\rho c_{p}\right)_{\mathrm{f}}+\phi\left(\rho c_{p}\right)_{\mathrm{s}}$
Fig. 1 Schematic diagram of the grooved enclosure

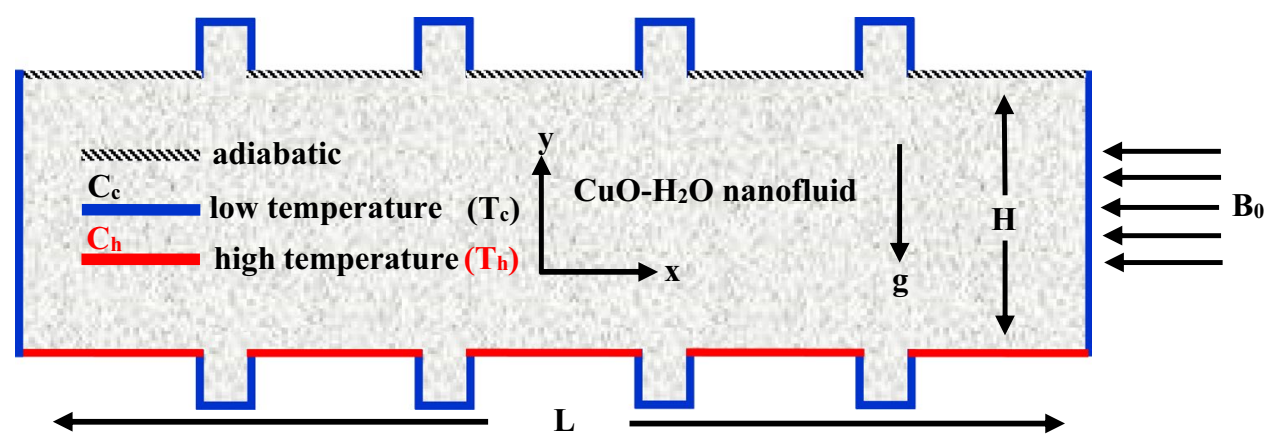

SN Applied Sciences A SPRINGer NATURE journa 
$\sigma_{\mathrm{nf}}=\sigma_{\mathrm{f}}\left[1+\frac{3(\sigma-1) \phi}{(\sigma+2)-(\sigma-1) \phi}\right], \quad \sigma=\sigma_{\mathrm{s}} / \sigma_{\mathrm{f}} \quad U \frac{\partial U}{\partial X}+V \frac{\partial U}{\partial Y}=-\frac{\partial P}{\partial X}+\frac{v_{\mathrm{nf}}}{v_{\mathrm{f}}} \operatorname{Pr}\left(\frac{\partial^{2} U}{\partial X^{2}}+\frac{\partial^{2} U}{\partial Y^{2}}\right)$

$k_{\mathrm{nf}}=\frac{k_{\mathrm{s}}+2 k_{\mathrm{f}}-2 \phi\left(k_{\mathrm{f}}-k_{\mathrm{s}}\right)}{k_{\mathrm{s}}+2 k_{\mathrm{f}}+\phi\left(k_{\mathrm{f}}-k_{\mathrm{s}}\right)} k_{\mathrm{f}}+\frac{\phi \rho_{\mathrm{s}} c_{p, \mathrm{~s}}}{2} \sqrt{\frac{2 K_{\mathrm{B}} T}{3 \pi d_{\mathrm{s}} \mu_{\mathrm{f}}}}$

$\begin{aligned} U \frac{\partial V}{\partial X}+V \frac{\partial V}{\partial Y}= & -\frac{\partial P}{\partial Y}+\frac{v_{\mathrm{nf}}}{v_{\mathrm{f}}} \operatorname{Pr}\left(\frac{\partial^{2} V}{\partial X^{2}}+\frac{\partial^{2} V}{\partial Y^{2}}\right) \\ & +\frac{\beta_{\mathrm{nf}}}{\beta_{\mathrm{f}}} \operatorname{Ra} \operatorname{Pr} \theta-\left(\frac{\sigma_{\mathrm{nf}}}{\sigma_{\mathrm{f}}}\right)\left(\frac{\rho_{\mathrm{f}}}{\rho_{\mathrm{nf}}}\right) \operatorname{PrHa}^{2} v\end{aligned}$

$\alpha_{\mathrm{nf}}=k_{\mathrm{nf}} /\left(\rho C_{p}\right)_{\mathrm{nf}}$

$\mu_{\mathrm{nf}}=\mu_{\mathrm{f}}\left(1+39.11 \phi+533.9 \phi^{2}\right)$.

$$
\begin{aligned}
U \frac{\partial \theta}{\partial X}+V \frac{\partial \theta}{\partial Y}= & \frac{\alpha_{\mathrm{nf}}}{\alpha_{\mathrm{f}}}\left(\frac{\partial^{2} \theta}{\partial X^{2}}+\frac{\partial^{2} \theta}{\partial Y^{2}}\right) \\
& +\frac{D_{\mathrm{B}}}{\mathrm{Le}}\left(\frac{\partial \phi}{\partial X} \frac{\partial \theta}{\partial X}+\frac{\partial \phi}{\partial Y} \frac{\partial \theta}{\partial Y}\right) \\
& +\frac{D_{\mathrm{T}}}{L e N_{\mathrm{BT}}}\left(\left(\frac{\partial \theta}{\partial X}\right)^{2}+\left(\frac{\partial \theta}{\partial Y}\right)^{2}\right) \\
& +\left(\frac{\sigma_{\mathrm{nf}}}{\sigma_{\mathrm{f}}}\right) \frac{\left(\rho c_{p}\right)_{\mathrm{f}}}{\left(\rho c_{p}\right)_{\mathrm{nf}}} \frac{\mathrm{Ha}^{2}}{\mathrm{Ra}} \mathrm{Ec}^{2}
\end{aligned}
$$

effect. Thus, the entropy generation due to various physi-

cal sources is given in dimensional form as $([32,33])$ :

$s=\frac{k_{\mathrm{nf}}}{T_{0}^{2}}\left[\left(\frac{\partial T}{\partial x}\right)^{2}+\left(\frac{\partial T}{\partial y}\right)^{2}\right]+\frac{\mu_{\mathrm{nf}}}{T_{0}}\left[2\left(\left(\frac{\partial u}{\partial x}\right)^{2}+\left(\frac{\partial v}{\partial y}\right)^{2}\right)+\left(\frac{\partial u}{\partial y}+\frac{\partial v}{\partial x}\right)^{2}\right]+\frac{\sigma_{\mathrm{nf}} B_{0}^{2} v^{2}}{T_{0}}$.

The appropriate boundary conditions for the present modeled are as follows:

$$
\begin{aligned}
\left(U \frac{\partial \phi}{\partial X}+V \frac{\partial \phi}{\partial Y}\right)= & \frac{\operatorname{Pr} D_{\mathrm{B}}}{\mathrm{Sc}}\left(\frac{\partial^{2} \phi}{\partial X^{2}}+\frac{\partial^{2} \phi}{\partial Y^{2}}\right) \\
& +\frac{\operatorname{Pr} D_{\mathrm{T}}}{S c N_{\mathrm{B}}}\left(\frac{\partial^{2} \theta}{\partial X^{2}}+\frac{\partial^{2} \theta}{\partial Y^{2}}\right) .
\end{aligned}
$$

1. On the grooved and vertical walls:

2. On the top horizontal walls:

$$
u=v=0, \frac{\partial T}{\partial y}=\frac{\partial C}{\partial y}=0 .
$$

3. On the bottom horizontal walls:

$$
u=v=0, T=T_{\mathrm{h}}, C=C_{\mathrm{h}} .
$$

The governing equations are to be non-dimensionalized using the following transformations:

Here, $\operatorname{Pr}=\frac{v_{f}}{\alpha_{f}}$ is the Prandtl number (ratio of momentum diffusivity to thermal diffusivity), $S c=\frac{v_{f}}{D_{B_{0}}}$ is the Schmidt number (ratio of momentum diffusivity to Brownian diffusivity), $\mathrm{Ha}^{2}=\frac{\sigma_{\mathrm{f}} B_{0}^{2} L^{2}}{\rho_{\mathrm{f}} \nu_{\mathrm{f}}}$ is the Hartmann number (ratio of magnetic force to viscous force), $R a=\frac{g \beta_{f}\left(T_{h}-T_{c}\right) L^{3}}{v_{f} \alpha_{f}}$ is the Rayleigh number (ratio of buoyancy force to viscous force), $L e=\frac{\alpha_{\mathrm{f}}}{D_{B_{0}} c_{p, s} \phi_{b}}$ is the Lewis number (ratio of thermal diffusivity to Brownian diffusivity) and $N_{\mathrm{BT}}=\frac{D_{B_{0}} \phi_{b} T_{c}}{D_{\mathrm{T}_{0}}\left(T_{\mathrm{h}}-T_{c}\right)}$ is the diffusivity ratio parameter (ratio of Brownian diffusivity to thermophoretic diffusivity).

$X=\frac{x}{H^{\prime}}, Y=\frac{y}{H^{\prime}}, U=\frac{u H}{\alpha_{\mathrm{f}}}, V=\frac{v H}{\alpha_{\mathrm{f}}}, P=\frac{p H^{2}}{\rho_{\mathrm{nf}} \alpha_{\mathrm{f}}}, D_{\mathrm{B}}=\frac{D_{\mathrm{B}}^{*}}{D_{\mathrm{B}_{0}}}, D_{\mathrm{T}}=\frac{D_{\mathrm{T}}^{*}}{D_{\mathrm{T}_{0}}}, \phi=\frac{\phi^{*}}{\phi_{\mathrm{b}}}$ and $\theta=\frac{T-T_{\mathrm{c}}}{T_{\mathrm{h}}-T_{\mathrm{c}}}$

where $D_{\mathrm{T}_{0}}=\left(0.26 \frac{k_{\mathrm{f}}}{2 k_{\mathrm{f}}+k_{\mathrm{s}}}\right) \frac{\mu_{\mathrm{f}}}{\rho_{\mathrm{f}}} \phi_{\mathrm{b}}$ and $D_{\mathrm{B}_{0}}=\frac{\kappa_{\mathrm{B}} T_{\mathrm{c}}}{3 \pi \mu_{\mathrm{f}} d_{\mathrm{s}}}$.

Therefore, non-dimensional governing equations are:

$\frac{\partial U}{\partial X}+\frac{\partial V}{\partial Y}=0$ 
The entropy generation in dimensionless form can now be obtained from Eq. (6) as follows:

$S_{\mathrm{T}}=\frac{k_{\mathrm{nf}}}{k_{\mathrm{f}}}\left[\left(\frac{\partial \theta}{\partial X}\right)^{2}+\left(\frac{\partial \theta}{\partial Y}\right)^{2}\right]+\chi \frac{\mu_{\mathrm{nf}}}{\mu_{\mathrm{f}}}\left[2\left(\left(\frac{\partial U}{\partial X}\right)^{2}+\left(\frac{\partial V}{\partial Y}\right)^{2}\right)+\left(\frac{\partial U}{\partial Y}+\frac{\partial V}{\partial X}\right)^{2}\right]+\chi \frac{\sigma_{\mathrm{nf}}}{\sigma_{\mathrm{f}}} H \mathrm{a}^{2} V^{2}$.

In Eq. (16), the first term on the right side represents dimensionless entropy generation due to heat transfer $\left(S_{H_{T}}\right)$, second term represents the dimensionless entropy generation due to fluid friction $\left(S_{\mathrm{FF}}\right)$ and the third term represents the dimensionless entropy generation due to magnetic effect $\left(S_{\mathrm{MF}}\right)$. Here, $\chi=\frac{\mu_{\mathrm{f}} T_{0}}{k_{\mathrm{f}}}\left(\frac{\alpha_{\mathrm{f}}}{T_{\mathrm{h}}-T_{\mathrm{c}}}\right)^{2}$ is called as irreversibility distribution ratio.

Therefore, Eq. (16) can be written as follows:

$S_{\mathrm{T}}=S_{\mathrm{HT}}+S_{\mathrm{FF}}+S_{\mathrm{MF}}$

where

$$
\begin{aligned}
& S_{\mathrm{HT}}=\frac{k_{\mathrm{nf}}}{k_{\mathrm{f}}}\left[\left(\frac{\partial \theta}{\partial X}\right)^{2}+\left(\frac{\partial \theta}{\partial Y}\right)^{2}\right] \\
& S_{\mathrm{FF}}=\chi \frac{\mu_{\mathrm{nf}}}{\mu_{\mathrm{f}}}\left[2\left(\left(\frac{\partial U}{\partial X}\right)^{2}+\left(\frac{\partial V}{\partial Y}\right)^{2}\right)+\left(\frac{\partial U}{\partial Y}+\frac{\partial V}{\partial X}\right)^{2}\right]
\end{aligned}
$$

$\mathrm{S}_{\mathrm{MF}}=\chi \frac{\sigma_{\mathrm{nf}}}{\sigma_{\mathrm{f}}} \mathrm{Ha}^{2} V^{2}$

$\mathrm{Be}=\frac{S_{\mathrm{HT}}}{S_{\mathrm{T}}}$.

Here, Be is the Bejan number which symbolizes the strength of entropy generation due to heat transfer irreversibility. At $\mathrm{Be}>\frac{1}{2}$, entropy generation is dominated by heat transfer irreversibility, and at $\mathrm{Be}<\frac{1}{2}$, entropy generation is dominated by fluid friction irreversibility. For $\mathrm{Be}=\frac{1}{2}$, the heat transfer and fluid friction irreversibility are equal.

The associated boundary conditions can be written in the dimensionless form as follows:

1. On the grooved and vertical walls:

$$
U=V=0, \theta=0, \phi=0 .
$$

2. On the top horizontal walls:

$$
U=V=0, \frac{\partial \theta}{\partial Y}=\frac{\partial \phi}{\partial Y}=0 .
$$

3. On the bottom horizontal walls:

$$
U=V=0, \theta=1, \phi=1 \text {. }
$$

\subsection{Evaluation of stream function, average Nusselt number, average temperature and average entropy generation}

\subsubsection{Stream function}

The fluid motion is displayed using stream function $(\psi)$ obtained from the velocity components $U$ and $V$. The relationships between the stream function and velocity components for two-dimensional flows are:

$U=\frac{\partial \psi}{\partial Y}$ and $V=-\frac{\partial \psi}{\partial X}$.

These can be written in a single equation as:

$\frac{\partial^{2} \psi}{\partial X^{2}}+\frac{\partial^{2} \psi}{\partial Y^{2}}=\frac{\partial U}{\partial Y}-\frac{\partial V}{\partial X}$.

In numerical computations, the positive sign of stream function indicates anticlockwise rotation and the negative sign of stream function denotes clockwise rotation of the flow circulation within the enclosure.

\subsubsection{Local and average Nusselt number}

The local Nusselt number in dimensional form is defined as [47]:

$\bar{N} u=-\frac{k_{\mathrm{nf}}}{k_{\mathrm{f}}} \frac{\partial T}{\partial y}$

which can be written in dimensionless form as $([15,33$, 47]):

$\mathrm{Nu}=-\frac{k_{\mathrm{nf}}}{k_{\mathrm{f}}} \frac{\partial \theta}{\partial Y}$

and the average Nusselt number along the heated wall can be calculated by using the following relation:

$\mathrm{Nu}=\frac{1}{L-0.8 H} \sum_{i=0}^{4} \int_{X_{2 i}}^{X_{2 i+1}} \mathrm{Nu} \mathrm{d} X$.

\subsubsection{Average temperature}

The average temperature of the fluid domain within the enclosure is estimated by the following expression: 
$\theta_{\mathrm{av}}=\int(\theta / \bar{V}) \mathrm{d} \bar{V}$

where $\bar{V}$ is the volume of the enclosure.

\subsubsection{Average entropy generation}

The dimensionless average entropy generation $S_{\text {avg }}$ can be computed by integrating Eq. (17) as:

$S_{\text {avg }}=\frac{1}{V} \int S_{\mathrm{T}} \mathrm{d} V=S_{\mathrm{HT}, \text { avg }}+S_{\mathrm{FF}, \text { avg }}+S_{\mathrm{MF}, \text { avg }}$.

Here, $S_{\mathrm{HT} \text {, avg }}, S_{\mathrm{FF}, \text { avg }}$ and $\mathrm{S}_{\mathrm{MF} \text {, avg }}$ denote the average entropy generation due to heat transfer, fluid friction and magnetic field effect, respectively.

\section{Mesh generation}

Mesh generation is the process of creating meshes by dividing a geometric domain into a set of sub-domains with high-quality cells like triangular or quadrilateral in two dimensions and tetrahedral or hexahedral in three dimensions, called finite element. The mesh needs to be fine in areas where the subsequent calculations are important. It is basically a discretization of a geometric domain on which the problem is to be solved. The meshing of complicated geometry is essential in the numerical solution of the boundary value problems arising in various fields of scientific and engineering applications. In the present study, a commercially developed mesh generator (COMSOL Multiphysics) is used for appropriate meshing. The mesh configuration of the present physical domain with triangular elements is presented in Fig. 2.

\section{Grid sensitivity test}

Grid convergence test has been performed using five types of different meshes consisting of $21,010,29,666,37,866$, 44,116 and 52,602 elements to obtain an appropriate grid

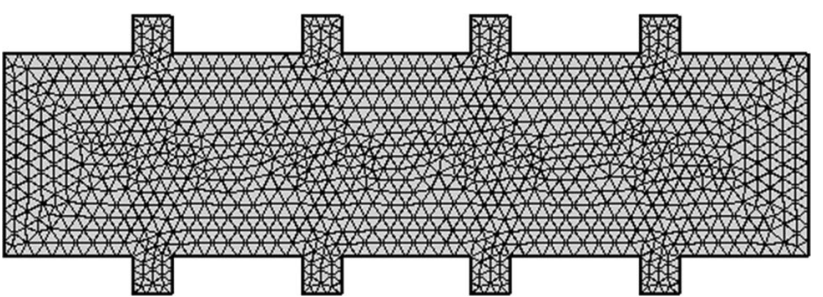

Fig. 2 Mesh generation of the grooved enclosure
Table 2 Grid sensitivity test at $\operatorname{Pr}=6.2, \mathrm{Ra}=10^{5}, \mathrm{Ha}=20, \phi=1 \%$, $\phi_{b}=2 \%, \mathrm{Sc}=10, D_{\mathrm{B}}=0.6, D_{T}=0.3$ and $\mathrm{Ec}=10^{-4}$

\begin{tabular}{llllll}
\hline $\begin{array}{l}\text { Nodes } \\
\text { (ele- } \\
\text { ments) }\end{array}$ & $\begin{array}{l}11,318 \\
(21,010)\end{array}$ & $\begin{array}{l}15,911 \\
(29,666)\end{array}$ & $\begin{array}{l}20,291 \\
(37,866)\end{array}$ & $\begin{array}{l}\mathbf{2 3 , 6 2 0} \\
\mathbf{( 4 4 , 1 1 6 )}\end{array}$ & $\begin{array}{l}27,964 \\
(52,602)\end{array}$ \\
\hline $\mathrm{Nu}_{\mathrm{av}}$ & 5.4901 & 5.6686 & 5.8111 & $\mathbf{5 . 9 0 1 4}$ & 5.9113 \\
\hline
\end{tabular}

size for accurate solution with minimum computational time. The average Nusselt number for different meshes is computed at $\operatorname{Pr}=6.2, \mathrm{Ra}=10^{5}, \mathrm{Ha}=20, \phi=1 \%, \phi_{b}=2 \%$, Sc $=10, D_{\mathrm{B}}=0.6, D_{T}=0.3$ and $\mathrm{Ec}=10^{-4}$ and presented in Table 2 and Fig. 3. The obtained results in Table 2 and Fig. 3 suggest that there will be no remarkable changes in average Nusselt number with the further refinement of grid procedure. Therefore, the grid size of 23,620 nodes and 44,116 elements is found to meet the requirements for accurate solution with minimum computational time for the present problem.

\section{Numerical method}

The numerical simulation of the governing Eqs. (11) to (15) associated with the boundary condition (22) to (24) has been carried out by using Galerkin weighted finite element method. In this simulation, Galerkin weighted residual method is implemented to convert the governing partial differential equations into a set of integral equations and the integral equations are:

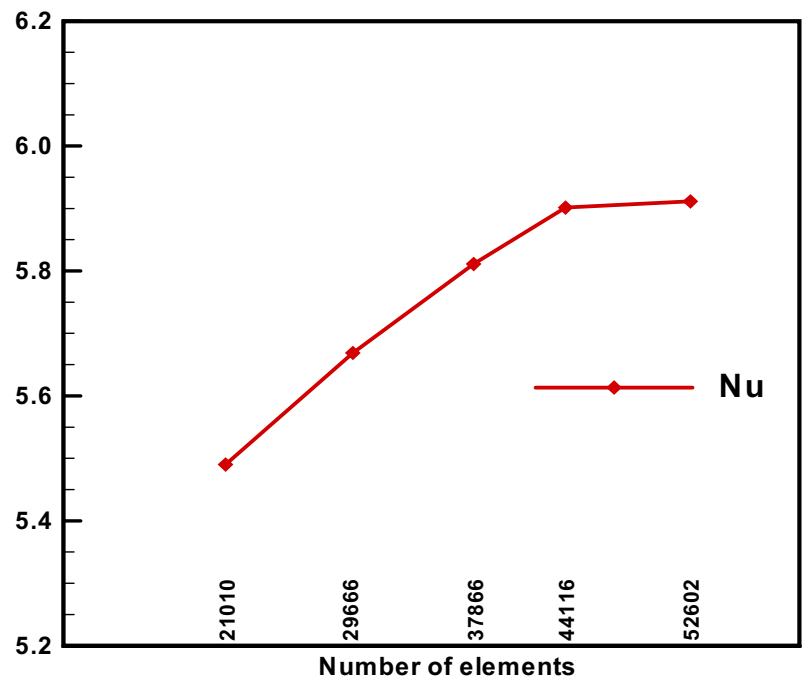

Fig. 3 Grid sensitivity test 
$\int_{A} N_{\alpha}\left(\frac{\partial U}{\partial X}+\frac{\partial V}{\partial Y}\right) d A=0$

$\int_{A} N_{\alpha}\left(U \frac{\partial U}{\partial X}+V \frac{\partial U}{\partial Y}\right) \mathrm{d} A=-\int_{A} H_{\lambda} \frac{\partial P}{\partial X} \mathrm{~d} A+\frac{v_{\mathrm{nf}}}{v_{\mathrm{f}}} \operatorname{Pr} \int_{A} N_{\alpha} \overline{\left(\frac{\partial^{2} U}{\partial X^{2}}+\frac{\partial^{2} U}{\partial Y^{2}}\right)} \mathrm{d} A$

$\int_{A} N_{\alpha}\left(U \frac{\partial V}{\partial X}+V \frac{\partial V}{\partial Y}\right) \mathrm{d} A=-\int_{A} H_{\lambda} \frac{\partial P}{\partial Y} \mathrm{~d} A+\frac{v_{\mathrm{nf}}}{v_{\mathrm{f}}} \operatorname{Pr} \int_{A} N_{\alpha}\left(\frac{\partial^{2} V}{\partial X^{2}}+\frac{\partial^{2} V}{\partial Y^{2}}\right) \mathrm{d} A$

$+\left(\frac{\beta_{\mathrm{nf}}}{\beta_{\mathrm{f}}}\right) \operatorname{Ra} \operatorname{Pr} \int_{A} N_{\alpha} \theta \mathrm{d} A-\left(\frac{\rho_{\mathrm{f}}}{\rho_{\mathrm{nf}}}\right)\left(\frac{\sigma_{\mathrm{nf}}}{\sigma_{\mathrm{f}}}\right) \mathrm{Ha}^{2} \operatorname{Pr} \int_{A} N_{\alpha} V \mathrm{~d} A$

$\int_{A} N_{\alpha}\left(U \frac{\partial \theta}{\partial X}+V \frac{\partial \theta}{\partial Y}\right) \mathrm{d} A=\frac{\alpha_{\mathrm{nf}}}{\alpha_{\mathrm{f}}} \int_{A} N_{\alpha}\left(\frac{\partial^{2} \theta}{\partial X^{2}}+\frac{\partial^{2} \theta}{\partial Y^{2}}\right) \mathrm{d} A+\frac{D_{\mathrm{B}}}{\text { Le }} \int_{A} N_{\alpha}\left(\frac{\partial \phi}{\partial X} \frac{\partial \theta}{\partial X}+\frac{\partial \phi}{\partial Y} \frac{\partial \theta}{\partial Y}\right) \mathrm{d} A$

$+\frac{D_{\mathrm{T}}}{\operatorname{LeN}_{\mathrm{BT}}} \int_{A} N_{\alpha}\left(\left(\frac{\partial \theta}{\partial X}\right)^{2}+\left(\frac{\partial \theta}{\partial Y}\right)^{2}\right) \mathrm{d} A+\left(\frac{\sigma_{\mathrm{nf}}}{\sigma_{\mathrm{f}}}\right) \frac{\left(\rho c_{p}\right)_{\mathrm{f}}}{\left(\rho c_{p}\right)_{\mathrm{nf}}} \frac{\mathrm{Ha} \mathrm{R}^{2}}{\mathrm{Ra}} \mathrm{EC} \int_{A} N_{\alpha} V^{2} \mathrm{~d} A$

$\int_{A} N_{\alpha}\left(U \frac{\partial \phi}{\partial X}+V \frac{\partial \phi}{\partial Y}\right) \mathrm{d} A=\frac{\operatorname{Pr} D_{\mathrm{B}}}{\mathrm{Sc}} \int_{A} N_{\alpha}\left(\frac{\partial^{2} \phi}{\partial X^{2}}+\frac{\partial^{2} \phi}{\partial Y^{2}}\right) \mathrm{d} A+\frac{\operatorname{Pr} D_{\mathrm{T}}}{\operatorname{Sc} N_{\mathrm{B} T}} \int_{A} N_{\alpha}\left(\frac{\partial^{2} \theta}{\partial X^{2}}+\frac{\partial^{2} \theta}{\partial Y^{2}}\right) \mathrm{d} A$.

Here, $A$ is the element area, $N_{\alpha}(\alpha=1,2, \ldots, 6)$ are the element shape functions or interpolation functions for the velocity components and temperature, and $H_{\lambda}(\lambda=1,2,3$. ) are the element shape function for the pressure. The Gaussian divergence theorem is introduced in Eqs. (31)-(35) to generate the boundary integral terms associated with the surface tractions and heat flux in the momentum and energy equations, and we obtained the following equations:

$\int_{A} N_{\alpha}\left(\frac{\partial U}{\partial X}+\frac{\partial V}{\partial Y}\right) \mathrm{d} A=0$ 


$$
\begin{array}{r}
\int_{A} N_{\alpha}\left(U \frac{\partial \phi}{\partial X}+V \frac{\partial \phi}{\partial Y}\right) \mathrm{d} A+\frac{\operatorname{Pr} D_{\mathrm{B}}}{\mathrm{Sc}} \int_{A}\left(\frac{\partial N_{\alpha}}{\partial X} \frac{\partial \phi}{\partial X}+\frac{\partial N_{\alpha}}{\partial Y} \frac{\partial \phi}{\partial Y}\right) \mathrm{d} A \\
+\frac{\operatorname{Pr} D_{\mathrm{T}}}{S c N_{\mathrm{BT}}} \int_{A}\left(\frac{\partial N_{\alpha}}{\partial X} \frac{\partial \theta}{\partial X}+\frac{\partial N_{\alpha}}{\partial Y} \frac{\partial \theta}{\partial Y}\right) \mathrm{d} A=\int_{A w} N_{\alpha} b_{\mathrm{w}} \mathrm{d} A_{\mathrm{w}}
\end{array}
$$

where $A_{x^{\prime}} A_{y}$ are the surface tractions along the outflow boundary $A_{0}$ and velocity components and fluid temperature or heat flux $\left(q_{\mathrm{w}}\right)$ and particle distribution $\left(b_{\mathrm{w}}\right)$ that flows into or out from the domain along wall boundary $A_{\mathrm{w}}$. The basic unknown for the above differential equations are the velocity components $(U, V)$, temperature $\theta$ and the pressure $P$. For the development of the finite element equations, the six-node triangular element is used in this work. All six nodes are associated with velocities as well as temperature, and only the three corner nodes are linked with pressure. This means that a lower-order polynomial is chosen for pressure which is satisfied through continuity equation. The velocity components, temperature profiles and linear interpolation for the pressure distribution according to their highest derivative orders for differential Eqs. (11) to (15) are given as:

$U(X, Y)=N_{\beta} U_{\beta}$
$V(X, Y)=N_{\beta} V_{\beta}$

$\theta(X, Y)=N_{\beta} \theta_{\beta}$

$\phi(X, Y)=N_{\beta} \phi_{\beta}$

$P(X, Y)=H_{\lambda} P_{\lambda}$

where $\beta=1,2, \ldots, 6$ and $\lambda=1,2,3$.

Substituting the element velocity component distributions, temperature distributions, particles distributions and the pressure distribution from Eqs. (41)-(45) into Eqs. (36) to (40), the finite element equations can be written in the following form:

$U_{\beta} \int_{A} N_{\alpha} N_{\beta, x} \mathrm{~d} A+V_{\beta} \int_{A} N_{\alpha} N_{\beta, y} \mathrm{~d} A=0$

$$
\begin{array}{r}
U_{\beta} U_{\gamma} \int_{A} N_{\alpha} N_{\beta} N_{\gamma, x} \mathrm{~d} A+V_{\beta} U_{\gamma} \int_{A} N_{\alpha} N_{\beta} N_{\gamma, y} \mathrm{~d} A+P_{\mu} \int_{A} H_{\lambda} H_{\mu, x} \mathrm{~d} A \\
+\frac{v_{\mathrm{nf}}}{v_{\mathrm{f}}} \operatorname{Pr} U_{\beta} \int_{A}\left(N_{\alpha, x} N_{\beta, x}+N_{\alpha, y} N_{\beta, y}\right) \mathrm{d} A=\int_{A_{0}} N_{\alpha} A_{x} \mathrm{~d} A_{0}
\end{array}
$$

$$
\begin{aligned}
U_{\beta} V_{\gamma} \int_{A} N_{\alpha} N_{\beta} N_{\gamma, x} \mathrm{~d} A+ & V_{\beta} V_{\gamma} \int_{A} N_{\alpha} N_{\beta} N_{\gamma, y} \mathrm{~d} A+P_{\mu} \int_{A} H_{\lambda} H_{\mu, y} \mathrm{~d} A+\frac{v_{\mathrm{nf}}}{v_{\mathrm{f}}} \operatorname{Pr} V_{\beta} \int_{A}\left(N_{\alpha, x} N_{\beta, x}+N_{\alpha, y} N_{\beta, y}\right) \mathrm{d} A \\
& -\left(\frac{\beta_{\mathrm{nf}}}{\beta_{\mathrm{f}}}\right) \operatorname{Ra} \operatorname{Pr} \theta_{\beta} \int_{A} N_{\alpha} N_{\beta} \mathrm{d} A+\left(\frac{\rho_{\mathrm{f}}}{\rho_{\mathrm{nf}}}\right)\left(\frac{\sigma_{\mathrm{nf}}}{\sigma_{\mathrm{f}}}\right) \operatorname{Ha}^{2} \operatorname{Pr} V_{\beta} \int_{A} N_{\alpha} N_{\beta} \mathrm{d} A=\int_{A_{0}} N_{\alpha} A_{y} \mathrm{~d} A_{0}
\end{aligned}
$$

$$
\begin{array}{r}
U_{\beta} \theta_{\gamma} \int_{A} N_{\alpha} N_{\beta} N_{\gamma, x} \mathrm{~d} A+V_{\beta} \theta_{\gamma} \int_{A} N_{\alpha} N_{\beta} N_{\gamma, y} \mathrm{~d} A+\frac{\alpha_{\mathrm{nf}}}{\alpha_{\mathrm{f}}} \theta_{\beta} \int_{A}\left(N_{\alpha, x} N_{\beta, x}+N_{\alpha, y} N_{\beta, y}\right) \mathrm{d} A \\
-\frac{D_{\mathrm{B}}}{\mathrm{Le}} \phi_{\beta} \theta_{\gamma} \int_{A} N_{\alpha}\left(N_{\alpha, x} N_{\beta, x}+N_{\alpha, y} N_{\beta, y}\right) \mathrm{d} A-\frac{D_{\mathrm{T}}}{L e N_{\mathrm{BT}}} \theta_{\beta}^{2} \int_{A} N_{\alpha}\left(N_{\beta, x}+N_{\beta, y}\right) \mathrm{d} A \\
-\left(\frac{\sigma_{\mathrm{nf}}}{\sigma_{\mathrm{f}}}\right) \frac{\left(\rho c_{p}\right)_{\mathrm{f}}}{\left(\rho c_{p}\right)_{\mathrm{nf}}} \frac{\mathrm{Ha}^{2}}{\mathrm{Ra}} \mathrm{ECV} V_{\beta}^{2} \int_{A} N_{\alpha} N_{\beta} \mathrm{d} A=\int_{A_{\mathrm{w}}} N_{\alpha} q_{\mathrm{w}} \mathrm{d} A_{\mathrm{w}}
\end{array}
$$

$$
\begin{aligned}
U_{\beta} \phi_{\gamma} \int_{A} N_{\alpha} N_{\beta} N_{\gamma, x} \mathrm{~d} A+V_{\beta} \phi_{\gamma} \int_{A} N_{\alpha} N_{\beta} N_{\gamma, y} \mathrm{~d} A+\frac{\operatorname{Pr} D_{\mathrm{B}}}{\mathrm{SC}} \phi_{\beta} \int_{A}\left(N_{\alpha, x} N_{\beta, x}+N_{\alpha, y} N_{\beta, y}\right) \mathrm{d} A \\
+\frac{\operatorname{Pr} D_{\mathrm{T}}}{\operatorname{Sc} N_{\mathrm{BT}}} \theta_{\beta} \int_{A}\left(N_{\alpha, x} N_{\beta, x}+N_{\alpha, y} N_{\beta, y}\right) \mathrm{d} A=\int_{A_{\mathrm{w}}} N_{\alpha} b_{\mathrm{w}} \mathrm{d} A_{\mathrm{w}} .
\end{aligned}
$$


Now we consider the coefficients in the above governing equations are as follows:

$K_{\alpha \beta^{x}}=\int_{A} N_{\alpha} N_{\beta, x} \mathrm{~d} A, \quad K_{\alpha \beta^{y}}=\int_{A} N_{\alpha} N_{\beta, y} \mathrm{~d} A, \quad K_{\alpha \beta \gamma^{x}}=\int_{A} N_{\alpha} N_{\beta}$ $N_{\gamma, x} \mathrm{~d} A$

$K_{\alpha \beta \gamma^{y}}=\int_{A} N_{\alpha} N_{\beta} N_{\gamma, y} \mathrm{~d} A, \quad K_{\alpha \beta}=\int_{A} N_{\alpha} N_{\beta} \mathrm{d} A, \quad S_{\alpha \beta^{x x}}=\int_{A} N_{\alpha, x}$ $N_{\beta, X} \mathrm{~d} A$

$S_{\alpha \beta^{y y}}=\int_{A} N_{\alpha, y} N_{\beta, x} \mathrm{~d} A, M_{\lambda \mu^{x}}=\int_{A} H_{\lambda} H_{\mu, x} \mathrm{~d} A, M_{\lambda \mu^{y}}=\int_{A} H_{\lambda} H_{\mu, y}$ $\mathrm{d} A$

$S_{\alpha \beta^{x} \gamma^{x}}=\int_{A} N_{\alpha} N_{\beta, y} N_{\gamma, x} d A, S_{\alpha \beta y} \gamma^{y}=\int_{A} N_{\alpha} N_{\beta, y} N_{\gamma, y} d A$

$Q_{\alpha^{u}}=\int_{A_{0}} N_{\alpha} A_{x} \mathrm{~d} A_{0}, \quad Q_{\alpha^{v}}=\int_{A_{0}} N_{\alpha} A_{y} \mathrm{~d} A_{0}, \quad Q_{\alpha^{\theta}}=\int_{A_{w}} N_{\alpha} q_{\mathrm{w}} \mathrm{d} A_{\mathrm{w}}$ ， $Q_{\alpha^{\phi}}=\int_{A_{\mathrm{w}}} N_{\alpha} b_{\mathrm{w}} \mathrm{d} A_{\mathrm{w}}$.

These element matrices are evaluated in a closed form for numerical simulation. Details of the derivation for these element matrices are omitted for brevity.

With the help of the above coefficients, the finite element equations can be written in the following type:

$K_{\alpha \beta^{x}} U_{\beta}+K_{\alpha \beta^{y}} V_{\beta}=0$

$K_{\alpha \beta \gamma^{x}} U_{\beta} U_{\gamma}+K_{\alpha \beta \gamma^{y}} V_{\beta} U_{\gamma}+M_{\lambda \mu^{x}} P_{\mu}+\frac{v_{\mathrm{nf}}}{v_{\mathrm{f}}} \operatorname{Pr} U_{\beta}\left(S_{\alpha \beta^{x x}}+S_{\alpha \beta^{y}}\right)=Q_{\alpha^{u}}$

$$
\begin{array}{r}
K_{\alpha \beta \gamma^{x}} U_{\beta} V_{\gamma}+K_{\alpha \beta \gamma^{y}} V_{\beta} V_{\gamma}+M_{\lambda \mu^{\nu}} P_{\mu}+\frac{v_{\mathrm{nf}}}{v_{\mathrm{f}}} \operatorname{Pr} V_{\beta}\left(S_{\alpha \beta^{x x}}+S_{\alpha \beta y y}\right)-\left(\frac{\beta_{\mathrm{nf}}}{\beta_{\mathrm{f}}}\right) \operatorname{Ra} \operatorname{Pr} K_{\alpha \beta} \theta_{\beta} \\
+\left(\frac{\rho_{\mathrm{f}}}{\rho_{\mathrm{nf}}}\right)\left(\frac{\sigma_{\mathrm{nf}}}{\sigma_{\mathrm{f}}}\right) \mathrm{Ha}^{2} \operatorname{Pr} K_{\alpha \beta} V_{\beta}=Q_{\alpha^{v}}
\end{array}
$$

$K_{\alpha \beta \gamma^{x}} U_{\beta} \theta_{\gamma}+K_{\alpha \beta \gamma^{y}} V_{\beta} \theta_{\gamma}+\frac{\alpha_{\mathrm{nf}}}{\alpha_{\mathrm{f}}} \theta_{\beta}\left(S_{\alpha \beta^{x x}}+S_{\alpha \beta^{y y}}\right)-\frac{D_{\mathrm{B}}}{\mathrm{Le}} \phi_{\beta} \theta_{\gamma}\left(S_{\alpha \beta^{x} \gamma^{x}}+S_{\alpha \beta^{y} \gamma^{y}}\right)$

$$
-\frac{D_{\mathrm{T}}}{\operatorname{LeN}_{\mathrm{BT}}} \theta_{\beta}^{2}\left(K_{\alpha \beta^{x}}+K_{\alpha \beta^{y}}\right)-\left(\frac{\sigma_{\mathrm{nf}}}{\sigma_{\mathrm{f}}}\right) \frac{\left(\rho c_{p}\right)_{\mathrm{f}}}{\left(\rho c_{p}\right)_{\mathrm{nf}}} \frac{\mathrm{Ha}^{2}}{\operatorname{Ra}} \mathrm{Ec} K_{\alpha \beta} V_{\beta}^{2}=Q_{\alpha^{\theta}}
$$

$K_{\alpha \beta \gamma^{x}} U_{\beta} \phi_{\gamma}+K_{\alpha \beta \gamma^{y}} V_{\beta} \phi_{\gamma}+\frac{\operatorname{Pr} D_{\mathrm{B}}}{\mathrm{SC}} \phi_{\beta}\left(S_{\alpha \beta^{x x}}+S_{\alpha \beta^{y y}}\right)+\frac{\operatorname{Pr} D_{\mathrm{T}}}{\operatorname{Sc} N_{\mathrm{BT}}} \theta_{\beta}\left(S_{\alpha \beta^{x x}}+S_{\alpha \beta^{y y}}\right)=Q_{\alpha^{\phi}}$.
Table 3 Comparison of the present results for average Nusselt number with those of Esfe et al. [53] and Oztop and Abu-Nada [54]

\begin{tabular}{llllll}
\hline Ra & $\phi$ & Present study (a) & Esfe et al. [53] (b) & $\begin{array}{l}\text { Oztop and Abu- } \\
\text { Nada [54] (c) }\end{array}$ & $|((a-b) / b) \times 100|$ \\
\hline $10^{3}$ & 0.00 & 1.008 & 1.008 & 1.004 & 0.00 \\
& 0.05 & 1.120 & 1.119 & 1.122 & 0.089 \\
& 0.10 & 1.254 & 1.253 & 1.251 & 0.079 \\
$10^{4}$ & 0.00 & 1.982 & 1.996 & 2.010 & 0.701 \\
& 0.05 & 2.085 & 2.097 & 2.122 & 0.572 \\
& 0.10 & 2.177 & 2.188 & 2.203 & 0.502 \\
$10^{5}$ & 0.00 & 3.936 & 3.993 & 3.983 & 1.427 \\
& 0.05 & 4.185 & 4.234 & 4.271 & 1.157 \\
& 0.10 & 4.417 & 4.459 & 4.440 & 0.941 \\
\hline
\end{tabular}


Fig. 4 a Comparison of temperature distribution along the mid-section of the cavity at $\operatorname{Ra}=10^{5}$ and $\operatorname{Pr}=0.7$. $\mathbf{b}$ Comparison of streamlines of the present solution (bottom) with the numerical solution of Ghasemi et al. [55] (top)

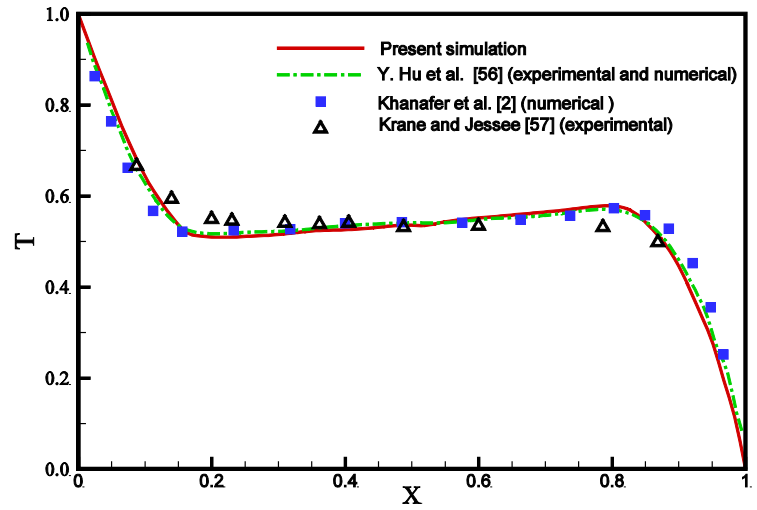

(a)

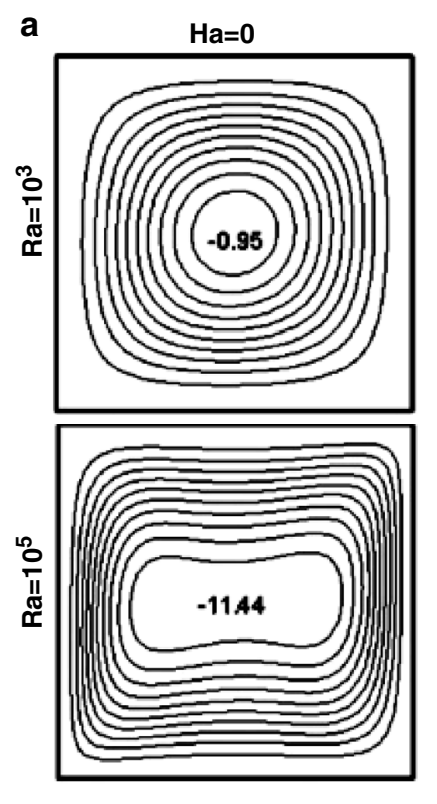

Ghasemi et al. [55]
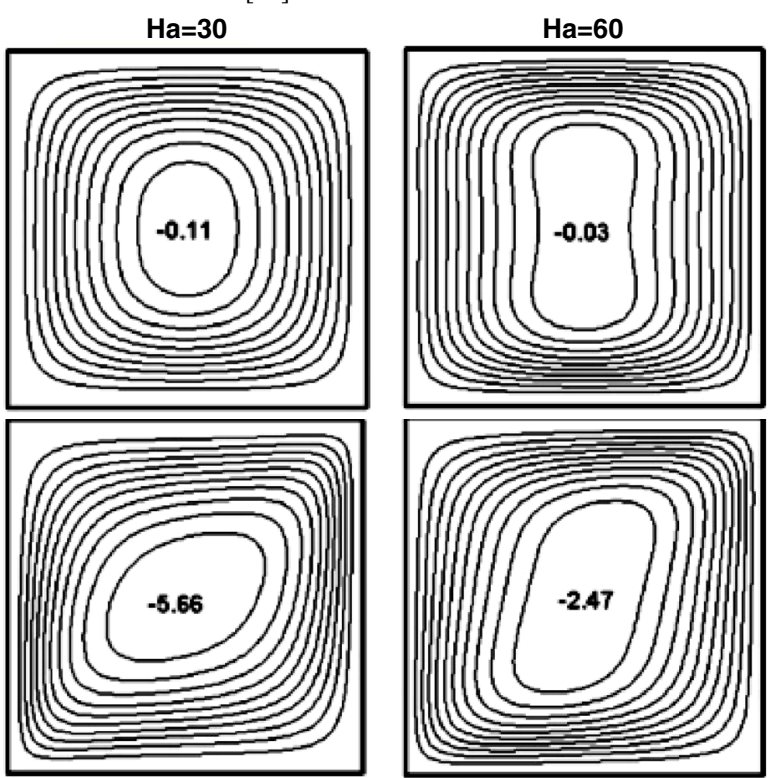

Present study [2020]
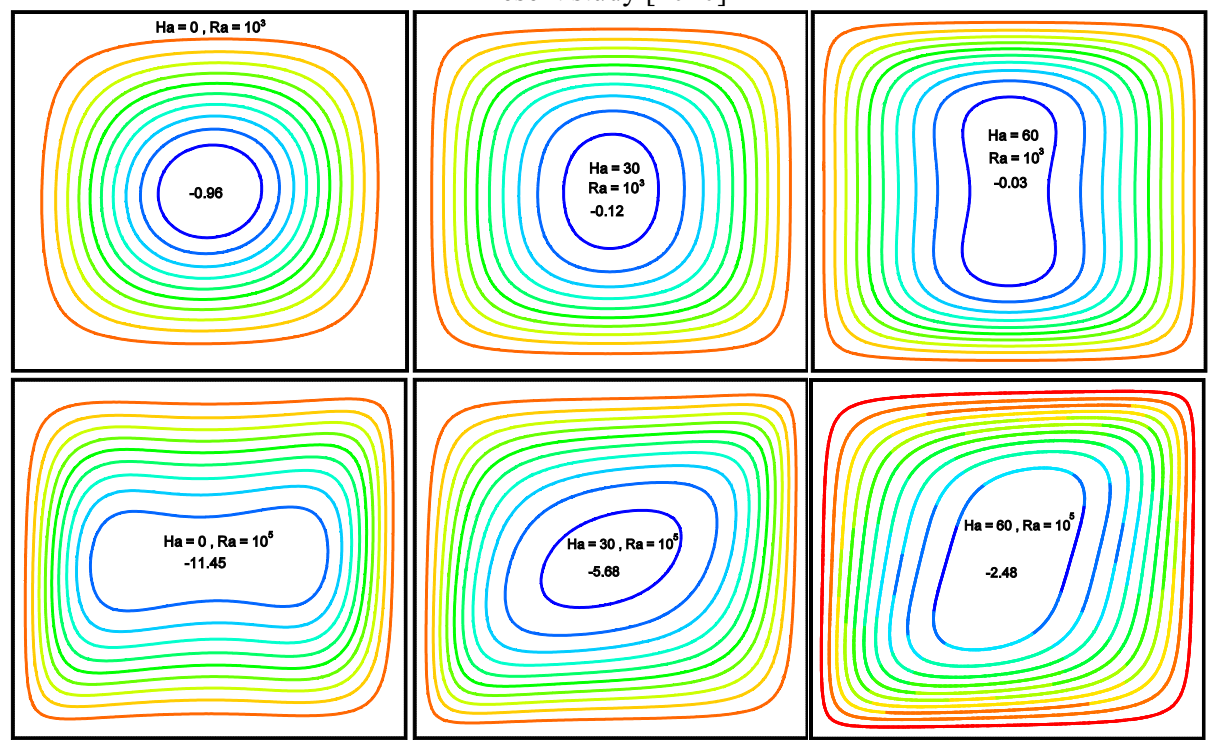

(b) 

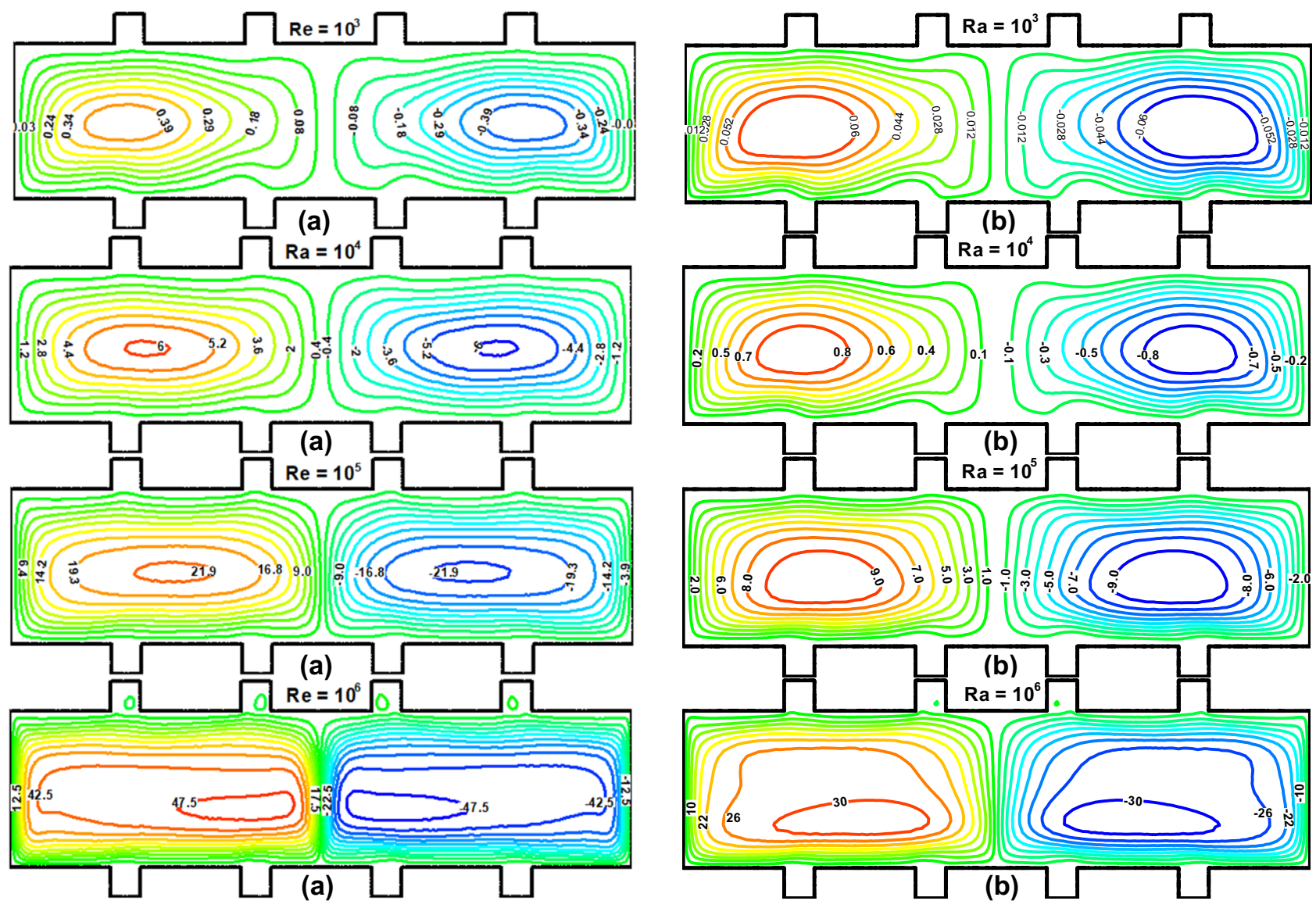

Fig. 5 Effect of Ra on streamlines for $\mathbf{a ~ H a}=20, \phi=1 \%$ and $\mathbf{b ~ H a}=50, \phi=1 \%$

Using Newton-Raphson method explained by Reddy [48], the obtained nonlinear Eqs. (51) to (55) are converted into linear algebraic equations. Finally, these linear equations are solved by employing triangular factorization method and reduced integration method expressed by Zeinkiewicz et al. [49]. The convergence criterion of the numerical solution along with error estimation has been set to $\left|\phi^{m+1}-\phi^{m}\right| \leq 10^{-5}$, where $m$ is the number of iteration and $\phi$ is a function of $U, V$ and $\theta$. The application of this simulation is well described by Taylor and Hood [50], Zienkiewicz and Taylor [51] and Dechaumphai. [52].

\section{Validation of numerical procedure}

The numerical procedure has been validated by comparing the present numerical results with the previously published numerical and experimental results of Khanafer et al. [2], Esfe et al. [53], Oztop and Abu-Nada [54], Ghasemi et al. [55], Hu et al. [56] and Krane and Jessee [57]. We have used our numerical code to simulate the identical problem of those of Esfe et al. [53], Oztop and Abu-Nada [54] and Ghasemi et al. [55] and present in terms of average Nusselt number in Table 3 and Table 4, respectively. Further comparisons have also been performed with the numerical and experimental results of Khanafer et al. [2], Ghasemi et al. [55], Hu et al. [56] and Krane and Jessee [57] and are displayed in Fig. 4a, b, respectively. It is evident that the computed results of the present study are in good agreement with the experimental and numerical results, which confirms the satisfactory accuracy of the present study.

\section{Results and discussion}

In this section, numerical results of streamlines, isotherms, isoconcentrations, average Nusselt number and entropy generation are obtained for magnetohydrodynamic natural convection flow of nanofluid within a grooved enclosure and presented graphically in Figs. 5, 6, 7, 8, 9, 10, 11, $12,13,14,15$ and 16 , respectively. The governing parameters are valued as: Rayleigh number (Ra) from $10^{3}$ to $10^{6}$, Hartmann number $(\mathrm{Ha})$ from 10 to 100 and volume fraction of nanoparticles $(\phi)$ from 0 to $5 \%$. The value of Prandtl number is fixed at 6.2 , and the remaining parameters are set as $\mathrm{Sc}=10, \phi_{b}=2 \%, D_{\mathrm{B}}=0.6, D_{T}=0.3$ and $\mathrm{Ec}=10^{-4}$ which 

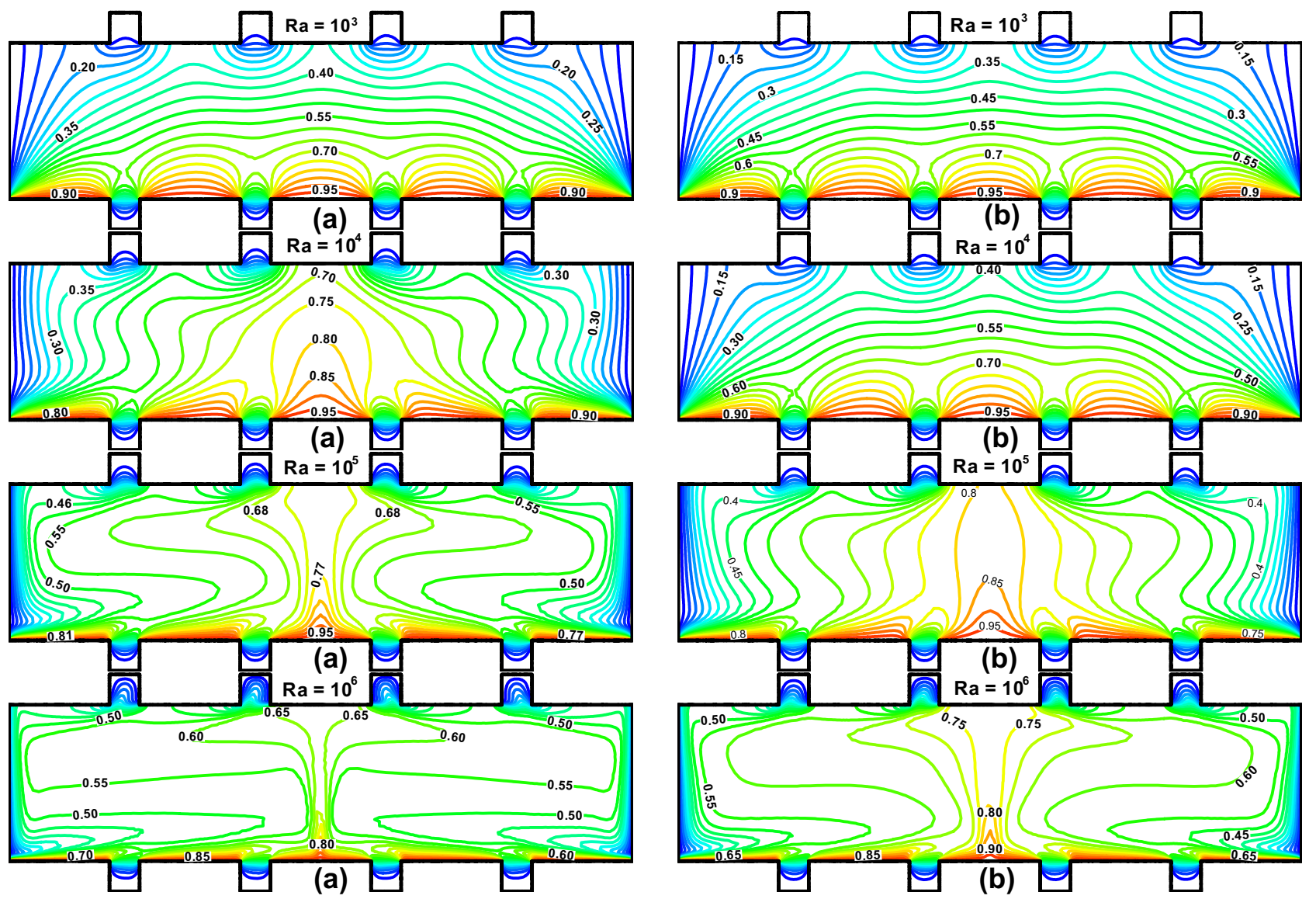

Fig. 6 Effect of Ra on isotherms for $\mathbf{a} \mathrm{Ha}=20, \phi=1 \%$ and $\mathbf{b} \mathrm{Ha}=50, \phi=1 \%$

are not mentioned in the text. In addition, the irreversibility distribution ratio is assumed as 0.001 to compute entropy generation for fluid friction and magnetic force.

Figure 5 illustrates the effect of Rayleigh number on the streamlines for different values of Hartmann number $(\mathrm{Ha}=20,50)$ at $\phi=1 \%$. From Fig. $5 \mathrm{a}$, it is seen that buoyancy-driven circulating flow is generated with two vortices inside the enclosure for all values of Ra due to the considered thermal management where the positive values of stream function indicate rotation is made in counterclockwise direction and negative values for clockwise direction. It is also clear in Fig. 5a that fluid near the bottom walls becomes hotter than fluid near the top walls due to applied thermal condition, which results in ascending the fluid near the midsection of the enclosure and then descending along the vertical cold walls. In addition, the structure of central cells is changed in shape as well as strength with the increasing Ra and the highest magnitude of flow circulation is also observed near the core regime of each vortex due to no-slip conditions. Moreover, the strength of flow circulation increases and the streamlines are more intensified near the side walls of the enclosure for the greater values of Ra. The reason behind it is that increasing Ra accelerates the influence of the buoyant force within the enclosure. On the other hand, in Fig. 5b, it is seen that at $\mathrm{Ha}=50$, the strength of flow circulation reduces for all $\mathrm{Ra}$ as compared to the case at $\mathrm{Ha}=20$ which shows a reduction in buoyancy force that causes a lower heat transfer rate, because the effect of Lorentz's force due to higher magnetic strength decreases the buoyancy force and retards the fluid motion within the enclosure. Moreover, the shape of the central cells changes remarkably with increasing Rayleigh number at higher $\mathrm{Ha}$, while the boundary cells are compressed toward the side walls.

Figure 6 demonstrates the isotherm contours for various Ra with two different values of Ha. From Fig. 6a, b, it is clear that at lower value of $\mathrm{Ra}$, the isotherms are almost similarly distributed, resulting in hot and cooled walls, which indicates conduction dominant heat transfer within the enclosure. In addition, isotherms are emanated from the heated surfaces and condensed toward the grooved entrances as well as lower corners of the enclosure, indicating a good heat transfer there, which plays a significant role in the temperature distribution as well as heat transfer rate. Moreover, in Fig. 6a, the trend of isotherms as well as 

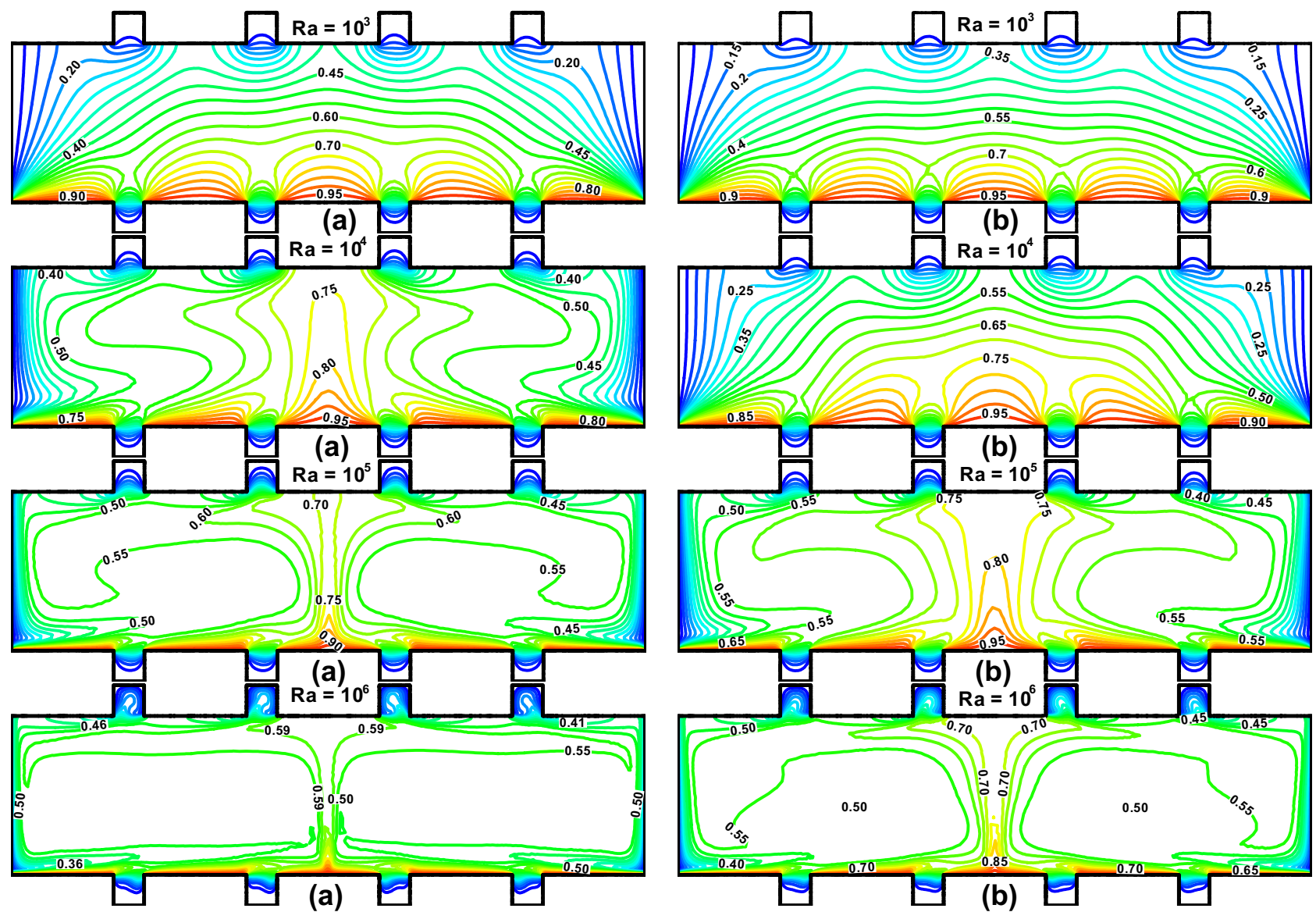

Fig. 7 Effect of Ra on isoconcentrations for $\mathbf{a} \mathrm{Ha}=20, \phi=1 \%$ and $\mathbf{b} \mathrm{Ha}=50, \phi=1 \%$

temperature plotting changes with increasing buoyancy effect due to greater Rayleigh number and isotherms are found to be more compressed toward the grooved and boundary walls of the enclosure. It is also seen that isotherms are more spreading from middle to side walls due to greater $\mathrm{Ra}$. Thus, the conduction dominant regime at lower Ra turns to convection dominant regime at higher Ra. Furthermore, the thermal boundary-layer thickness reduces with increasing $R a$, which leads to an increase in heat transfer rate. Besides this, the isotherms are affected slightly due to a higher value of Hartmann number at $\mathrm{Ha}=50$. These effects are noticeable for greater Ra where the temperature gradient reduces with higher $\mathrm{Ha}$.

The influence of Rayleigh number on isoconcentration contours with varying $\mathrm{Ha}$ is presented in Fig. 7. From Fig. $7 \mathrm{a}$, at lower Rayleigh number $\left(\mathrm{Ra}=10^{3}\right)$, it is observed that the isoconcentration contours are almost similarly distributed from bottom to top within the enclosure, whereas at higher values of Rayleigh number $\left(\mathrm{Ra} \geq 10^{4}\right)$ the concentration contours are crowded near the side walls as well as grooved areas of the enclosure, resulting in steep concentration gradient there. Moreover, isoconcentration contours are spaced out near the core region of the enclosure, which indicates a lower-concentration difference there. Furthermore, the thickness of mass boundary layer close to the bottom walls reduces with an increase in Rayleigh number, because the higher temperature gradient for greater Ra transports more particles from hot region to cold region due to thermophoretic force. On the other hand in Fig. 7b, it is seen that the variation of isoconcentration distribution with $\mathrm{Ra}$ is influenced by the greater Ha because the fluid movement due to buoyant force decreases for stronger magnetic field effect. Thus, particles distribution is more sensitive with greater $\mathrm{Ra}$ in the presence of lower magnetic field effect.

Figure 8 represents the streamlines under the effects of Rayleigh number with two different values of nanoparticle volume fraction at $\mathrm{Ha}=20$. From Fig. 8, it is evident that the shapes of the convection circulations remain unchanged with the variation of $\phi$ from 1 to $5 \%$. The numerical results presented in Fig. 8 a, b indicate that increasing strength of flow circulation due to increasing Ra declines with the higher concentration of nanoparticles. The physics behind it is that dispersed nanoparticles into the base fluid 

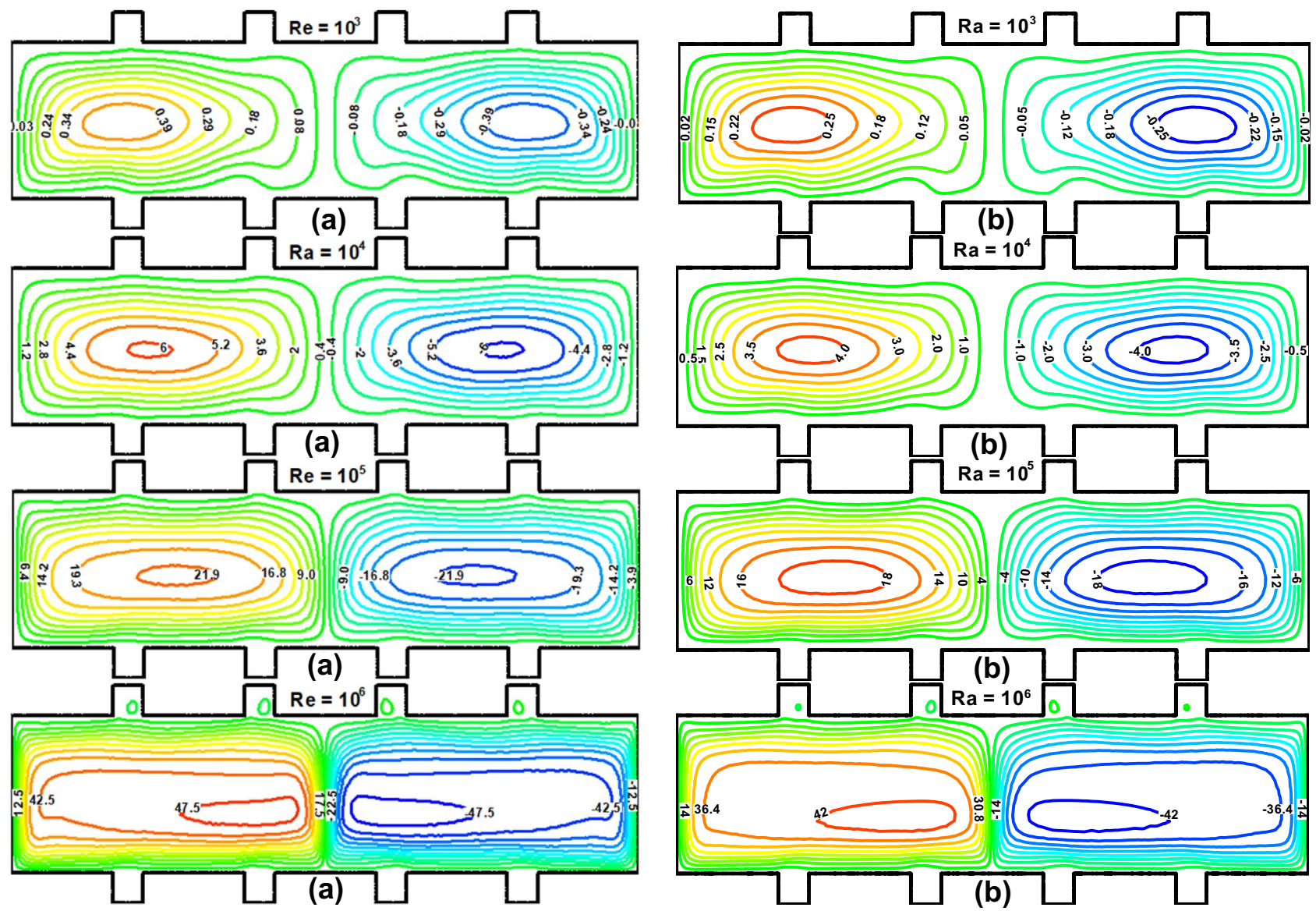

Fig. 8 Effect of Ra on streamlines for $\mathbf{a ~ H a}=20, \phi=1 \%$ and $\mathbf{b ~ H a}=20, \phi=5 \%$

increase the density of nanofluid, which leads to slowing down the fluid motion.

Figure 9 depicts the isotherm plots for different volume fractions with varying Ra. From these figures, it is clear that at each value of $R a$, the pattern of isotherms is almost analogous for varying volume fractions. Thus, the streamlines and isotherms distributions are insensitive for the variation of Ra than nanoparticle volume fraction, which indicates that the effects of natural convection parameters (Ra) are dominant than the effects of nanoparticle volume fraction.

The variation of isoconcentration distribution for different values of Ra with the selected values of $\phi$ is presented in Fig. 10. Figure 10 shows that at lower Ra, isoconcentration contours are qualitatively similar to the contours in Fig. 7. In addition, it is seen that the isoconcentration curves are symmetric and almost similarly distributed with rising $\phi$ from 1 to $5 \%$ with varying Ra up to $10^{5}$, whereas this variation is remarkable at $\mathrm{Ra}=10^{6}$. The physical fact behind it is that temperature distribution within the enclosure is dominated by conduction heat transfer for varying volume fractions from 1 to $5 \%$, which results in that temperature gradient remains almost similar, and also has symmetrical flow due to the same variation in volume fraction with identical boundary conditions. It is important to note that the isoconcentration plotting changes significantly with varying Rayleigh numbers as compared to $\phi$, which indicates the domination of Ra on $\phi$.

The local entropy generation of this study is a consequence of mostly heat transfer irreversibility, which is presented in Fig. 11a-d. In Fig. 11a-d, at lower Ra, it is seen that small entropy is produced near the junctions of the walls and also close to the bottom regime of the enclosure. Moreover, entropy generations near the bottom walls are much stronger than those near the upper walls. It is also observed that local entropy generation increases within the enclosure with increasing Ra. Because greater effects of Ra lead to enhancing the fluid motion along with higher temperature gradient as well as convection heat transfer. In addition, typical entropy is found near the middle of the enclosure, resulting in beneficial temperature gradient and convective heat transfer for greater values of $\mathrm{Ra}$.

On the other hand, a greater effect of $\mathrm{Ha}(\mathrm{Ha}=50)$ causes a small reduction in temperature gradient as well as flow circulations which diminishes entropy generation 

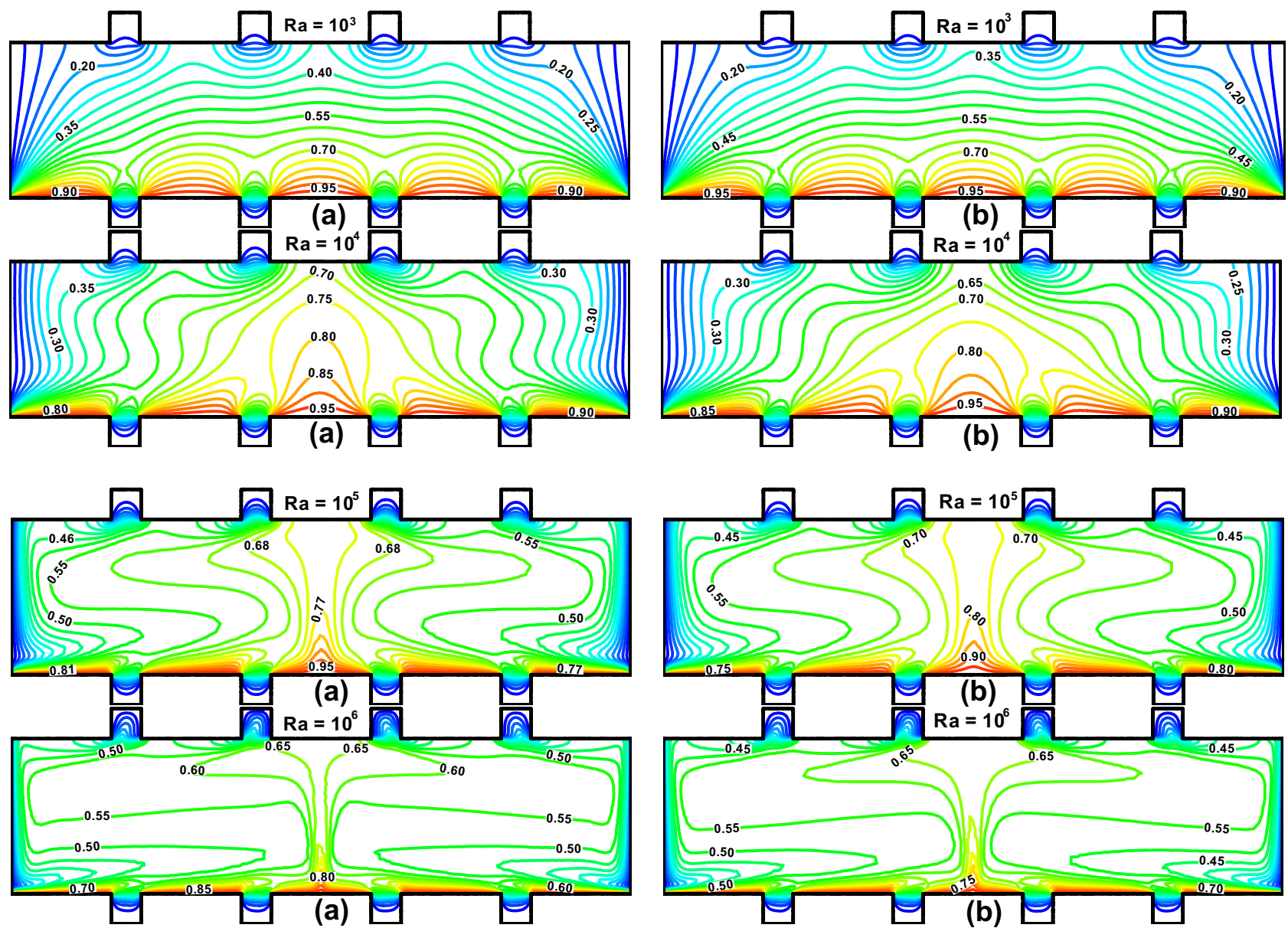

Fig. 9 Effect of Ra on isotherms for $\mathbf{a} \mathrm{Ha}=20, \phi=1 \%$ and $\mathbf{b} \mathrm{Ha}=20, \phi=5 \%$

within the enclosure, which is shown in Fig. 11b. Besides these, Fig. $11 \mathrm{c}$ reveals that smaller amount of entropy is generated in base fluid than nanofluids (shown in Fig. 11a). The reason behind it is that nanofluid has a greater thermal conductivity, which causes a higher heat transfer rate compared to base fluid. Further addition of nanoparticles into base fluid enhances the thermal conductivity as well as heat transfer coefficient, which causes higher entropy generation within the enclosure. Thus, more entropy generation takes place due to higher concentration of nanoparticles for all Ra at lower Hartmann number, which is clear in Fig. 11 a, d.

Figure 12 shows the average Nusselt number at the bottom heated walls for varying Rayleigh numbers with different values of Hartmann number and solid volume fraction of nanoparticles. From this figure, it is observed that average Nusselt number increases significantly with the increase in $\mathrm{Ra}$, which signifies that heat transfer rate increases with increasing $R a$. These are expected because greater Ra causes stronger flow circulation within the enclosure. Moreover, in Fig. 12a, it is also seen that the heat transfer profiles decline remarkably with the higher values of $\mathrm{Ha}$. The fact behind it is that applied magnetic field acts transverse to the buoyancy force and produces more temperature with the flow field and hence reduces the temperature difference. On the other hand, in Fig. 12b, the increasing rate of heat transfer due to an increase in $\mathrm{Ra}$ accelerates noticeably for the increase in volume fraction of nanoparticles, because the addition of nanoparticles increases the thermal conductivity of nanofluid, which results in enhancing the heat transfer capability of the nanofluid. In numerical computation, it is also found that heat transfer rate increases by $104.66 \%, 95.71 \%, 80.12 \%$ and $59.01 \%$ at the different strengths of magnetic field $(\mathrm{Ha}=10,20,50,100)$ with the variation in Ra from $10^{3}$ to $10^{6}$, whereas heat transfer rate increases by $87.77 \%$, $95.71 \%, 103.12 \%$ and $109.50 \%$ at the particle loading of $0 \%, 1 \%, 3 \%$ and $5 \%$ for the same variation of Ra with $\mathrm{Ha}=20$.

Figure 13 represents the average temperature in nanofluid and base fluid for varying $\mathrm{Ra}, \mathrm{Ha}$ and $\phi$. From Fig. 13 , it is seen that mean temperature increases considerably with 

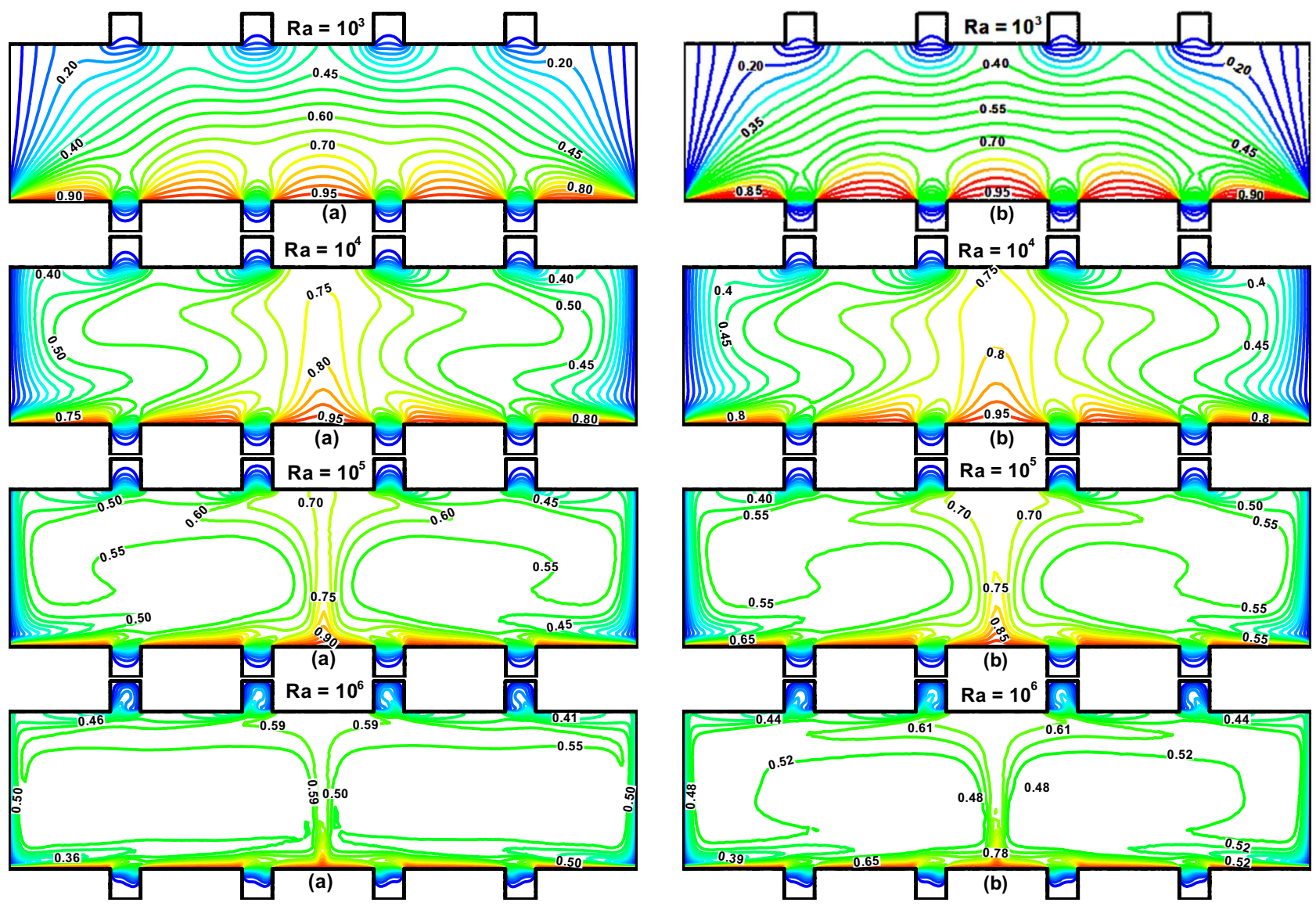

Fig. 10 Effect of Ra on isoconcentrations for $\mathbf{a} \mathrm{Ha}=20, \phi=1 \%$ and $\mathbf{b} \mathrm{Ha}=20, \phi=5 \%$

increasing $\mathrm{Ha}$ and $\mathrm{Ra}$, whereas it decreases significantly with increasing $\phi$. The reason behind it is that interaction of magnetic field with flowing fluid particles produces temperature within the fluid domain, which leads to a rise in mean temperature within the fluid domain, and increased thermal conductivity due to addition of nanoparticles to base fluid enhances the heat transfer capability. Moreover, an average temperature is greater in base fluid compared to that in nanofluid.

Figure 14 represents the vertical velocity profiles $(V)$ for a horizontal plane located at the midsection of the enclosure. In Fig. 14a, b, the plotted values of velocity components indicate the direction of fluid motion inside the enclosure. Comparing the velocity profiles in both figures, it is evident that magnitude of velocity components decreases with the increase in magnetic field strength and nanoparticle volume fraction for each value of Rayleigh number. Moreover, the velocity components become higher with increasing Ra in both cases. In addition, it is clear that the strength of fluid flow along the horizontal plane reduces significantly with Hartmann number than volume fraction. The maximum reduction in velocity components is obtained at the maximum nanoparticles concentration (5\%) of $24.17 \%$ at $\mathrm{Ra}=10^{3}, 20.31 \%$ at $\mathrm{Ra}=10^{4}$ and $11.79 \%$ at $\mathrm{Ra}=10^{5}$ compared to the base fluid, which reveals the domination of convective force over the particles loading in base fluid.

Figure 15 shows the variations of $S_{\mathrm{HT} \text {,avg }}, S_{\mathrm{FF}, \text { avg }}$ and $S_{\mathrm{MF} \text {,avg }}$ for a range of Ra at the different values of $\mathrm{Ha}$ and $\phi$, respectively. From Figs. 5, 6 and 12, it is visible that increasing Ra leads to an increase in the flow velocity and temperature gradient within the enclosure and hence the heat transfer rate. Accordingly, the effects of heat transfer irreversibility, fluid friction irreversibility and magnetic field irreversibility are augmented with the increasing Ra, which results in enhancing the entropy generation tools $S_{\mathrm{HT} \text {,avg, }} S_{\mathrm{FF}, \text { avg }}$ and $S_{\mathrm{MF} \text {,avg, }}$ respectively. It should be noted that the increasing rate of average entropy generations is more prominent in the higher range of $\mathrm{Ra}$ than in the lower range. Moreover, higher values of $\mathrm{Ha}$ reduce the flow circulation and temperature gradient and hence convection heat transfer rate (discussed in the earlier sections). As a result, entropy generation due to heat transfer and fluid friction decrease significantly with increasing $\mathrm{Ha}$, which are shown in Fig. 15a. It is also observed in Fig. 15a that entropy generation due to magnetic filed increases with 

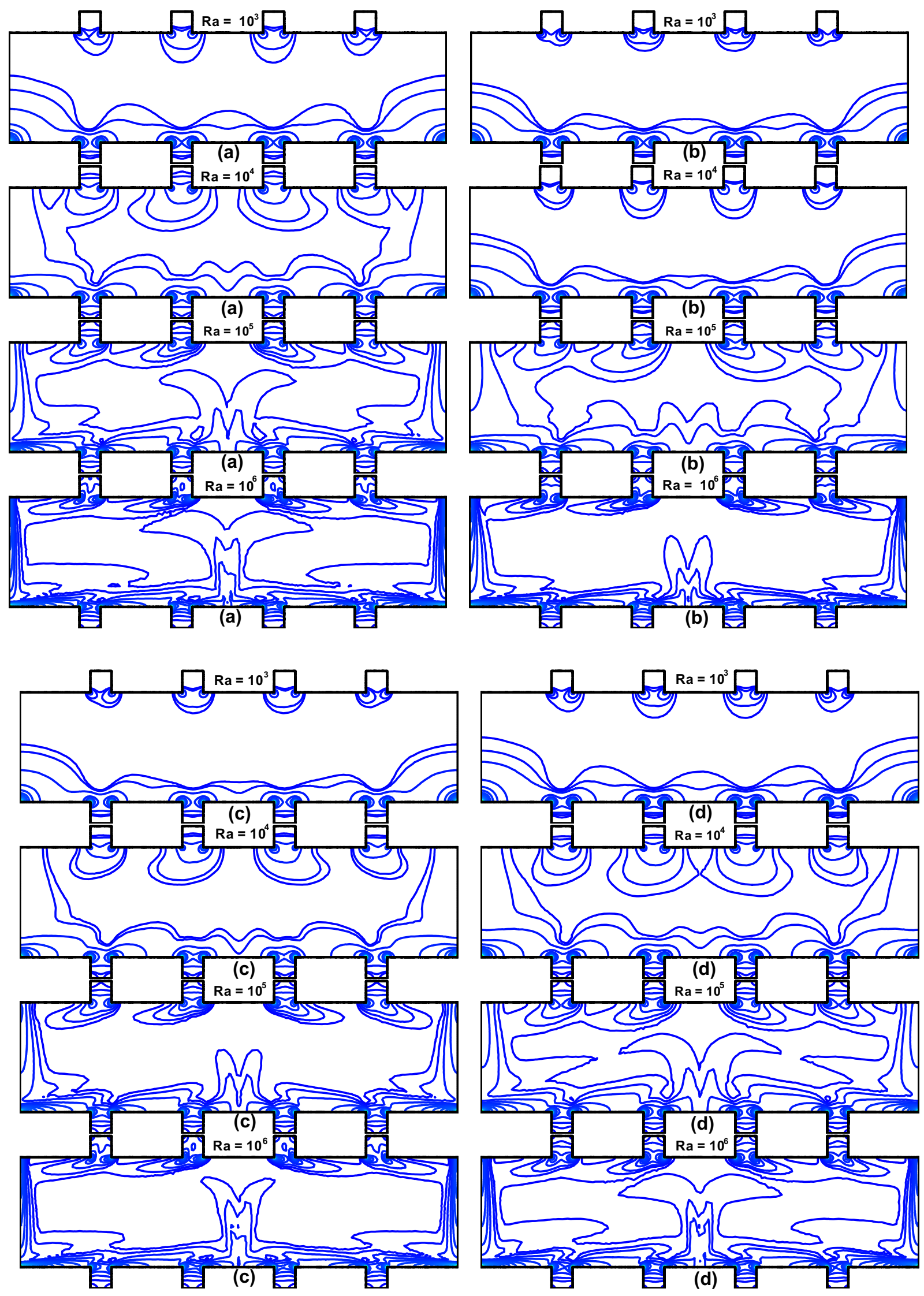

Fig. 11 Effect of Ra on local entropy for $\mathbf{a} \mathrm{Ha}=20, \phi=1 \%$ and $\mathbf{b} \mathrm{Ha}=50, \phi=1 \%$. Effect of Ra on local entropy for $\mathbf{c} \mathrm{Ha}=20, \phi=0 \%$ and $\mathbf{d} \mathrm{Ha}=20, \phi=5 \%$ 
(a)

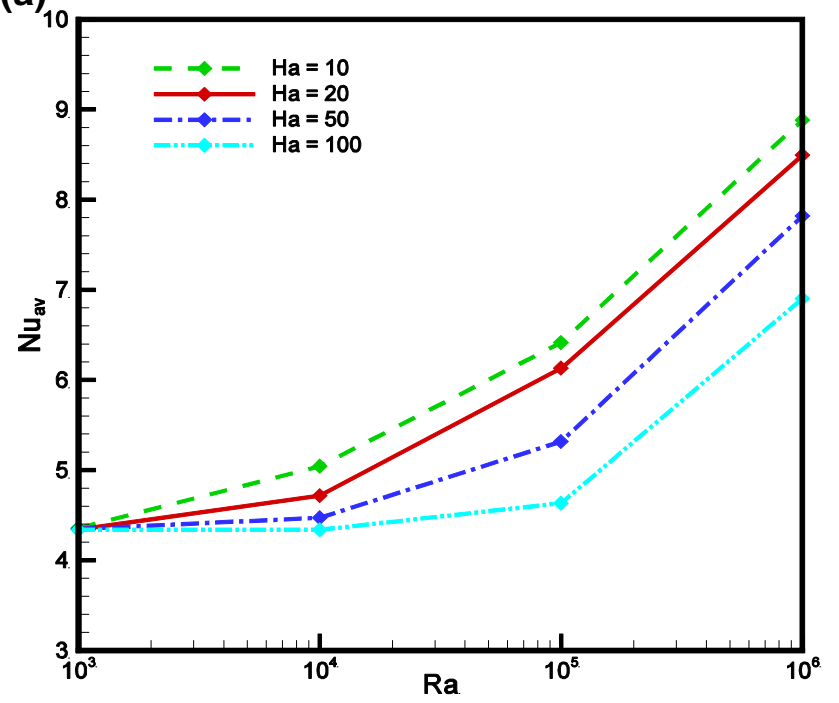

(b)

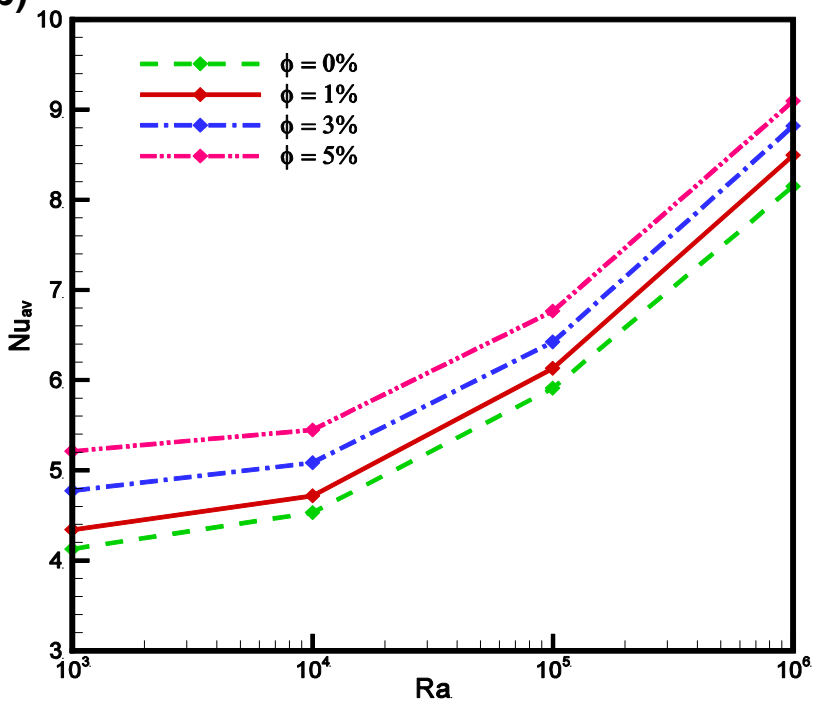

Fig. 12 Average Nusselt number plots against Ra with varying $\mathbf{a} \mathrm{Ha}$ and $\mathbf{b} \phi$

(a)

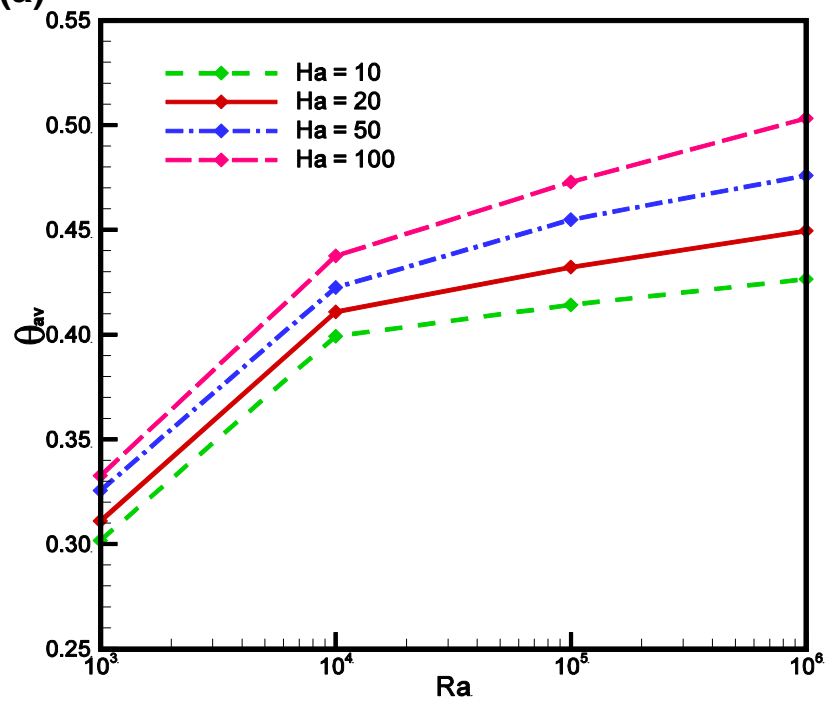

(b)

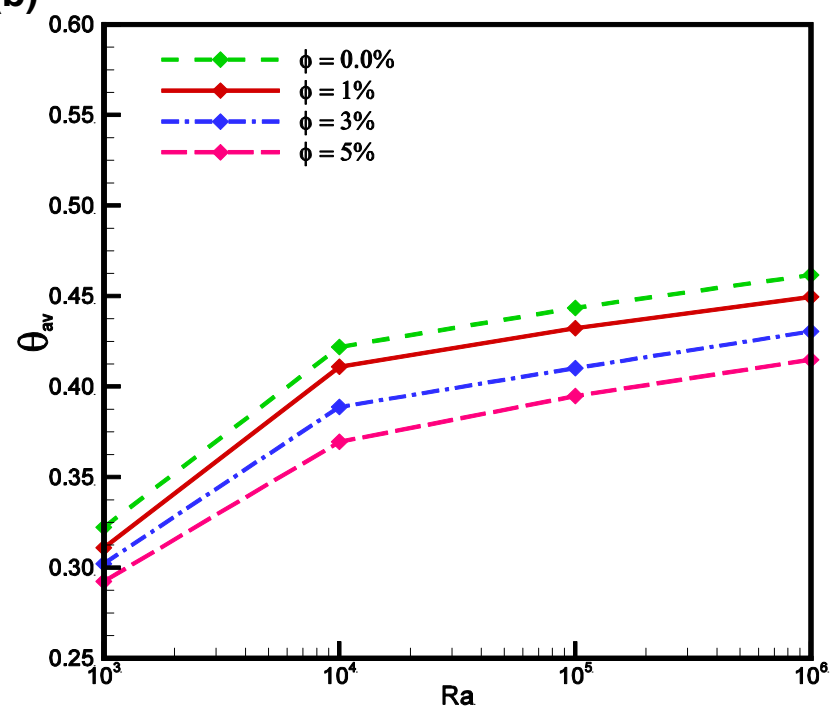

Fig. 13 Average temperature plots against Ra with varying $\mathbf{a} \mathrm{Ha}$ and $\mathbf{b} \phi$

the increase in $\mathrm{Ha}$ because the magnetic field irreversibility is proportional to squared magnetic strength. On the other hand, in Fig. 15b, it is seen that the entropy generation due to heat transfer and fluid friction enhances for the higher concentration of nanoparticles into base fluid because higher concentration of nanoparticles increases the heat transfer rate and fluid friction with the flow domain. Moreover, magnetic field irreversibility reduces with an increase in volume fraction. Consequently, entropy generation due to magnetic field reduces with an increase in volume fraction.
Figure 16 shows the variation of Bejan number against Ra for different values of Hartmann number and volume fraction of nanoparticles. It should be noted that the Bejan number is resulted form of the ratio of irreversibility distributions. From Fig. 16, it is evident that the Bejan number has a relatively highest value (near to unity) at lower Rayleigh number and lowest value (near to zero) at higher Rayleigh number, which indicates that Bejan number reduces with the increase in Rayleigh number, because at lower Rayleigh number the entropy generation tools due to various irreversibility distributions are lowest, whereas 

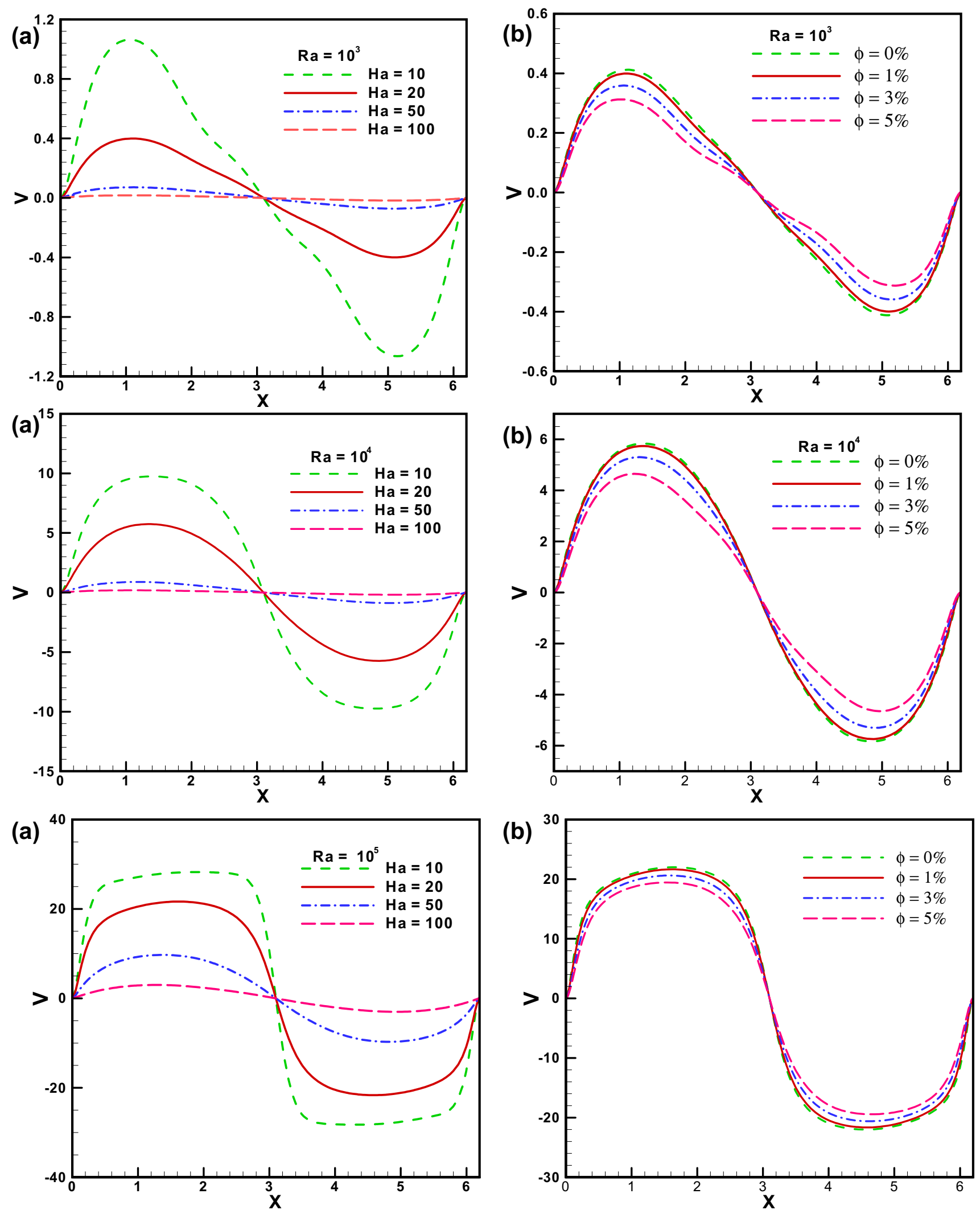

Fig. 14 Vertical velocity component ( $V$ plots against Ra with varying $\mathbf{a} \mathrm{Ha}$ and $\mathbf{b} \phi$ 

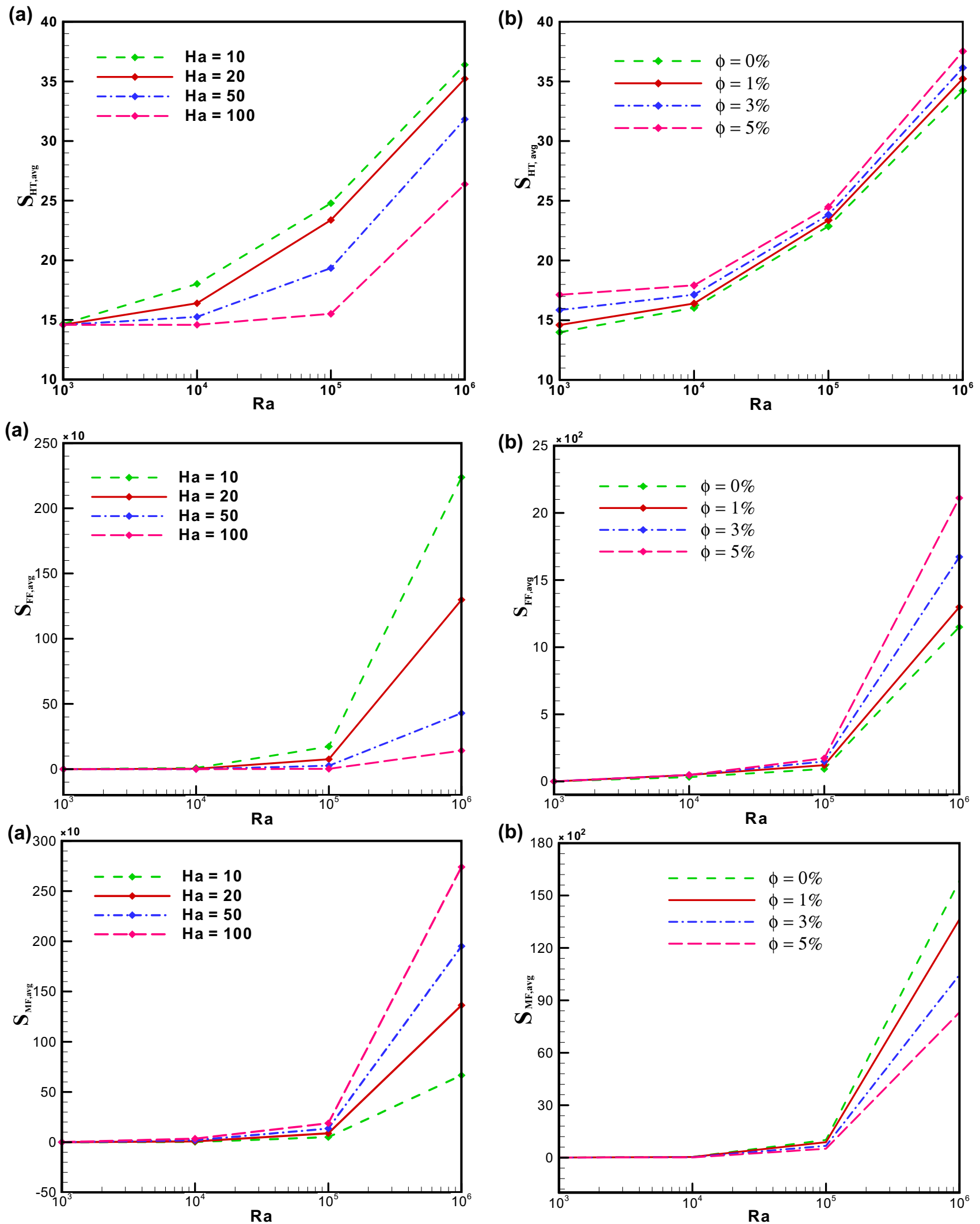

(b)

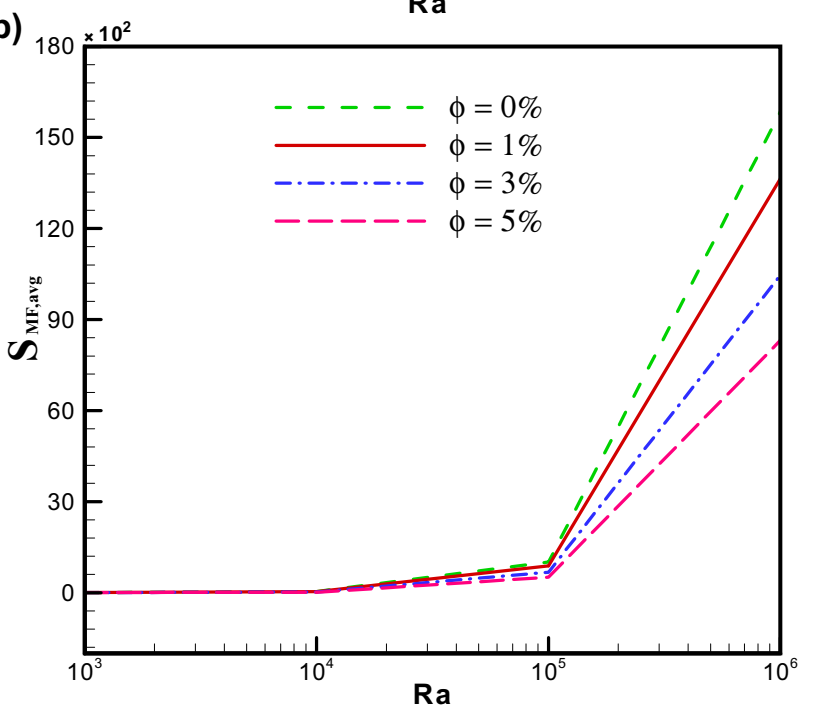

Fig. 15 Effect of Ra on $S_{\mathrm{HT}, \text { avg }} S_{\mathrm{FF}, \text { avg }}$ and $S_{\mathrm{MF} \text {,avg }}$ with varying a Ha and $\mathbf{b} \phi$ 
(a)

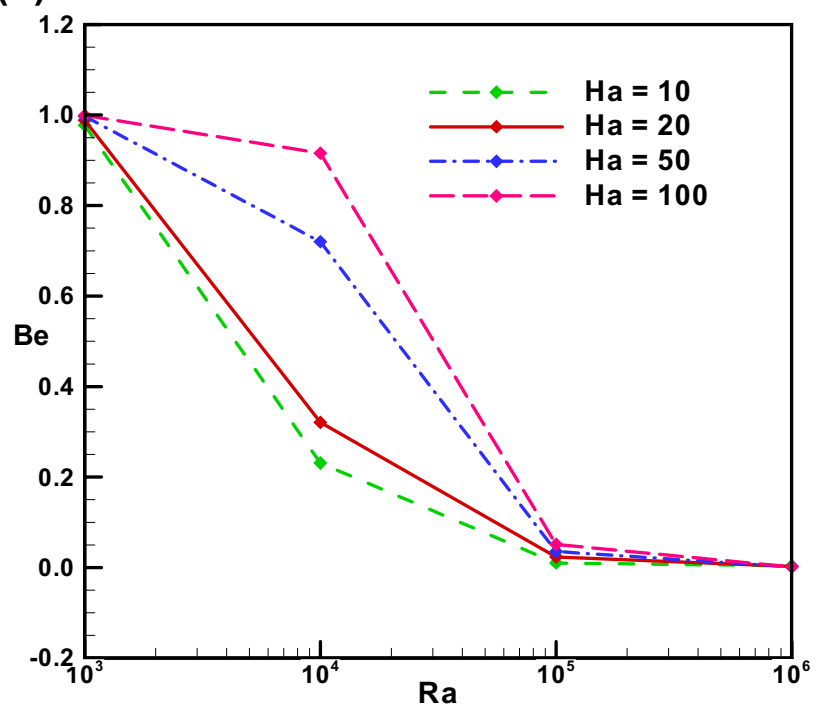

Fig. 16 Effect of Ra on Be with varying $\mathbf{a} \mathrm{Ha}$ and $\mathbf{b} \phi$

entropy generation tools are highest at higher values of Rayleigh number (shown in Fig. 15). In addition, convective flow is more intense at higher Rayleigh number compared to lower Rayleigh number which also affects the Bejan number. Moreover, it is observed that Bejan number increases with increasing both magnetic field strength and volume fraction of nanoparticles. These are consistent with the physical consequences of the relevant parameters.

\section{Conclusions}

In the present study, the effects of magnetic field on natural convection and entropy generation in a grooved enclosure filled with nanofluid have been studied numerically. The non-dimensional governing equations have been solved using Galerkin finite element method. Computations have been performed to analyze the effects of pertinent parameters on the fluid flow, temperature, particles distribution, heat transfer rate and entropy generations, respectively. The important conclusions based on the results and discussion of this analysis can be compiled as:

1. Fluid flow strength accelerates significantly with increasing $\mathrm{Ra}$ and decelerates with an augmentation in magnetic field strength and nanoparticle volume fraction. Isotherms and particles distributions become more concentrated with greater $\mathrm{Ra}$ and lower $\mathrm{Ha}$ as well as $\phi$.

2. The temperature as well as particles distribution changes remarkably with increasing Hartmann number and slightly for volume fraction.

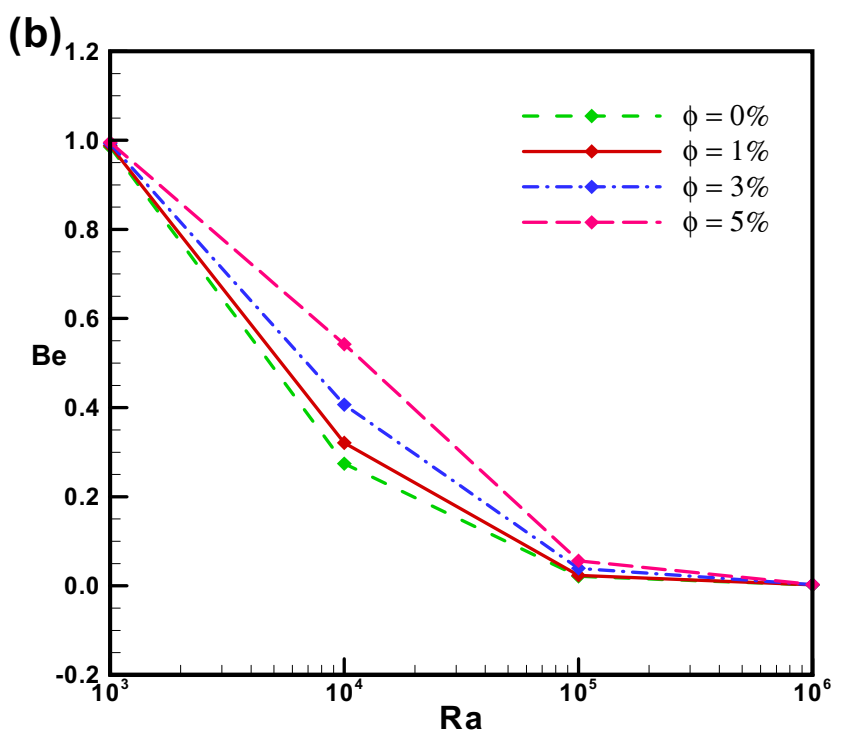

3. The increase in Ra increases the convective heat transfer coefficient as well as entropy generation tools, while Bejan number decreases with Ra. In addition, highest variation occurred in the range of $10^{5}$ to $10^{6}$.

4. The increase in magnetic field strength decreases the heat transfer rate and entropy generation due to heat transfer as well as fluid friction, whereas entropy generation due to magnetic force is increased.

5. Heat transfer rate and entropy generation due to heat transfer as well as fluid friction increases with increasing volume fraction, whereas entropy generation due to magnetic force is declined.

6. Heat transfer irreversibility dominates the entropy generation over the fluid friction irreversibility at lower $\mathrm{Ra}$ for all $\mathrm{Ha}$ and $\phi$, whereas higher values of Ra take the reverse behaviors.

\section{Compliance with ethical standards}

Conflict of interest The authors declare that they have no conflict of interest.

\section{References}

1. Choi SUS, Estman AJ (1995) Enhancing thermal conductivity of fluids with nanoparticles. ASME-Publications-Fed 231:99-106

2. Khanafer K, Vafai K, Lightstone M (2003) Buoyancy-driven heat transfer enhancement in a two-dimensional enclosure utilizing nanofluids. Int J Heat Mass Transf 46(19):3639-3653 
3. Jou RY, Tzeng SC (2006) Numerical research of nature convective heat transfer enhancement filled with nanofluids in rectangular enclosures. Int Commun Heat Mass Transfer 33(6):727-736

4. Tiwari RK, Das MK (2007) Heat transfer augmentation in a twosided lid-driven differentially heated square cavity utilizing nanofluids. Int J Heat Mass Transf 50(9-10):2002-2018

5. Kakaç S, Pramuanjaroenkij A (2009) Review of convective heat transfer enhancement with nanofluids. Int J Heat Mass Transf 52(13-14):3187-3196

6. Ghodsinezhad H, Sharifpur M, Meyer JP (2016) Experimental investigation on cavity flow natural convection of $\mathrm{Al}_{2} \mathrm{O}_{3}$-water nanofluids. Int Commun Heat Mass Transfer 76:316-324

7. Goodarzi H, Akbari OA, Sarafraz MM, Karchegani MM, Safaei MR, Shabani S, Ahmadi G (2019) Numerical simulation of natural convection heat transfer of nanofluid with $\mathrm{Cu}, \mathrm{MWCNT}$, and Al2O3 nanoparticles in a cavity with different aspect ratios. J Therm Sci Eng Appl 11(6):061020

8. Izadi M, Behzadmehr A, Shahmardan MM (2015) Effects of inclination angle on mixed convection heat transfer of a nanofluid in a square cavity. Int J Comput Methods Eng Sci Mech 16(1):11-21

9. Izadi M, Mehryan SAM, Sheremet MA (2018) Natural convection of CuO-water micropolar nanofluids inside a porous enclosure using local thermal non-equilibrium condition. J Taiwan Inst Chem Eng 88:89-103

10. Sabour M, Ghalambaz M, Chamkha A (2017) Natural convection of nanofluids in a cavity: criteria for enhancement of nanofluids. Int J Numer Meth Heat Fluid Flow 27(7):1504-1534

11. Roy NC (2018) Natural convection of nanofluids in a square enclosure with different shapes of inner geometry. Phys Fluids 30(11):113605

12. Bondarenko DS, Sheremet MA, Oztop HF, Ali ME (2019) Natural convection of $\mathrm{Al}_{2} \mathrm{O}_{3} / \mathrm{H}_{2} \mathrm{O}$ nanofluid in a cavity with a heat-generating element. Heatline visualization. Int J Heat Mass Transf 130:564-574

13. Buongiorno J (2006) Convective transport in nanofluids. J Heat Transf 128(3):240-250

14. Elshehabey HM, Ahmed SE (2015) MHD mixed convection in a lid-driven cavity filled by a nanofluid with sinusoidal temperature distribution on the both vertical walls using Buongiorno's nanofluid model. Int J Heat Mass Transf 88:181-202

15. Noghrehabadi A, Samimi Behbahan A, Pop I (2015) Thermophoresis and Brownian effects on natural convection of nanofluids in a square enclosure with two pairs of heat source/sink. Int J Numer Methods Heat Fluid Flow 25(5):1030-1046

16. Motlagh SY, Soltanipour $\mathrm{H}$ (2017) Natural convection of $\mathrm{Al}_{2} \mathrm{O}_{3}$-water nanofluid in an inclined cavity using Buongiorno's two-phase model. Int J Therm Sci 111:310-320

17. Bourantas GC, Loukopoulos VC (2014) MHD natural-convection flow in an inclined square enclosure filled with a micropolarnanofluid. Int J Heat Mass Transf 79:930-944

18. Kasaeipoor A, Ghasemi B, Aminossadati SM (2015) Convection of Cu-water nanofluid in a vented T-shaped cavity in the presence of magnetic field. Int J Therm Sci 94:50-60

19. Job VM, Gunakala SR (2016) Unsteady MHD free convection nanofluid flows within a wavy trapezoidal enclosure with viscous and Joule dissipation effects. Numer Heat Transf Part A Appl 69(4):421-443

20. Rahman MM, Alam MS, Al-Salti N, Eltayeb IA (2016) Hydromagnetic natural convective heat transfer flow in an isosceles triangular cavity filled with nanofluid using two-component nonhomogeneous model. Int J Therm Sci 107:272-288

21. Ahrar AJ, Djavareshkian MH (2016) Lattice Boltzmann simulation of a Cu-water nanofluid filled cavity in order to investigate the influence of volume fraction and magnetic field specifications on flow and heat transfer. J Mol Liq 215:328-338
22. M'hamed B, Sidik NAC, Yazid MNAWM, Mamat R, Najafi G, Kefayati GHR (2016) A review on why researchers apply external magnetic field on nanofluids. Int Commun Heat Mass Transf 78:60-67

23. Ali MM, Alim MA, Akhter R, Ahmed SS (2017) MHD natural convection flow of $\mathrm{CuO} /$ water nanofluid in a differentially heated hexagonal enclosure with a tilted square block. Int J Appl Comput Math 3(1):1047-1069

24. Dixit DD, Pattamatta A (2019) Natural convection heat transfer in a cavity filled with electrically conducting nano-particle suspension in the presence of magnetic field. Phys Fluids 31(2):023302

25. Alsoy-Akgün N (2019) Effect of an uniform magnetic field on unsteady natural convection of nanofluid. J Taibah Univ Sci 13(1):1073-1086

26. Izadi M, Maleki NM, Pop I, Mehryan SAM (2019) Natural convection of a hybrid nanofluid subjected to non-uniform magnetic field within porous medium including circular heater. Int J Numer Methods Heat Fluid Flow 29(4):1211-1231

27. Bejan A (1979) A study of entropy generation in fundamental convective heat transfer. J Heat Transf 101(4):718-725

28. Bouchoucha AEM, Bessaih R (2015) Natural convection and entropy generation of nanofluids in a square cavity. Int $J$ Heat Technol 33(4):1-10

29. Mejri I, Mahmoudi A, Abbassi MA, Omri A (2014) Magnetic field effect on entropy generation in a nanofluid-filled enclosure with sinusoidal heating on both side walls. Powder Technol 266:340-353

30. Meshram P, Bhardwaj S, Dalal A, Pati S (2016) Effects of the inclination angle on natural convection heat transfer and entropy generation in a square porous enclosure. Numer Heat Transf Part A Appl 70(11):1271-1296

31. Abbaszadeh M, Ababaei A, Arani AAA, Sharifabadi AA (2017) MHD forced convection and entropy generation of $\mathrm{CuO}$-water nanofluid in a microchannel considering slip velocity and temperature jump. J Braz Soc Mech Sci Eng 39(3):775-790

32. Mehmood K, Hussain S, Sagheer M (2017) Mixed convection in alumina-water nanofluid filled lid-driven square cavity with an isothermally heated square blockage inside with magnetic field effect: introduction. Int J Heat Mass Transf 109:397-409

33. Hussain S, Ahmed SE, Akbar T (2017) Entropy generation analysis in MHD mixed convection of hybrid nanofluid in an open cavity with a horizontal channel containing an adiabatic obstacle. Int J Heat Mass Transf 114:1054-1066

34. Alnajem MHS, Alsabery Al, Hashim I (2019) Entropy generation and natural convection in a wavy-wall cavity filled with a nanofluid and containing an inner solid cylinder. IOP Conf Ser Mater Sci Eng 518(3):032044

35. Woo-Sung HAN, Seok-Ho RHI (2011) Thermal characteristics of grooved heat pipe with hybrid nanofluids. Therm Sci 15(1):195-206

36. Sharma AK, Mahapatra PS, Manna NK, Ghosh K (2015) Mixed convection heat transfer in a grooved channel in the presence of a baffle. Numer Heat Transf Part A 67:1097-1118

37. Kumar LGK, Kumar SR, Subudhi S (2016) Experimental study of the turbulent free convection over horizontal smooth or grooved surfaces in an open cavity. Heat Mass Transf 52(2):245-253

38. Job VM, Gunakala SR (2017) Mixed convection nanofluid flows through a grooved channel with internal heat generating solid cylinders in the presence of an applied magnetic field. Int J Heat Mass Transf 107:133-145

39. Ali MM, Alim MA, Ahmed SS (2018) Numerical simulation of hydromagnetic natural convection flow in a grooved enclosure filled with $\mathrm{CuO}$-water nanofluid considering brownian motion. Int J Appl Comput Math 4:125. https://doi.org/10.1007/s4081 9-018-0563-1 
40. Das S, Jana RN, Makinde OD (2015) Mixed convective magnetohydrodynamic flow in a vertical channel filled with nanofluids. Eng Sci Technol Int J 18(2):244-255

41. Hussain S, Mehmood K, Sagheer M (2016) MHD mixed convection and entropy generation of water-alumina nanofluid flow in a double lid driven cavity with discrete heating. J Magn Magn Mater 419:140-155

42. Sheikholeslami M, Gorji-Bandpy M, Ganji DD (2013) Numerical investigation of $\mathrm{MHD}$ effects on $\mathrm{Al}_{2} \mathrm{O}_{3}$-water nanofluid flow and heat transfer in a semi-annulus enclosure using LBM. Energy 60:501-510

43. Selimefendigil F, Öztop HF (2014) Numerical study of MHD mixed convection in a nanofluid filled lid driven square enclosure with a rotating cylinder. Int J Heat Mass Transf 78:741-754

44. Maxwell JC (1873) A treatise on electricity and magnetism, vol 2. Oxford University Press, Cambridge

45. Pak BC, Cho YI (1998) Hydrodynamic and heat transfer study of dispersed fluids with submicron metallic oxide particles. Exp Heat Transf Int J 11(2):151-170

46. Cui W, Shen Z, Yang J, Wu S (2014) Modified prediction model for thermal conductivity of spherical nanoparticle suspensions (nanofluids) by introducing static and dynamic mechanisms. Ind Eng Chem Res 53(46):18071-18080

47. Nasrin R, Alim MA, Chamkha AJ (2012) Buoyancy-driven heat transfer of water- $\mathrm{Al}_{2} \mathrm{O}_{3}$ nanofluid in a closed chamber: effects of solid volume fraction, Prandtl number and aspect ratio. Int J Heat Mass Transf 55(25-26):7355-7365

48. Reddy JN (1993) An introduction to finite element analysis. McGraw-Hill, New-York

49. Zeinkiewicz OC, Taylor RL, Too JM (1971) Reduced integration technique in general analysis of plates and shells. Int J Numer Methods Eng 3:275-290
50. Taylor C, Hood P (1973) A numerical solution of the NavierStokes equations using the finite element technique. Comput Fluids 1(1):73-100

51. Zienkiewicz OC, Taylor RL (1991) The finite element method, 4th edn. McGraw-Hill, New York

52. Dechaumphai $P$ (1999) Finite element method in engineering, 2nd edn. Chulalongkorn University Press, Bangkok

53. Esfe MH, Arani AAA, Yan W-M, Ehteram H, Aghaie A, Afrand M (2016) Natural convection in a trapezoidal enclosure filled with carbon nanotube-EG-water nanofluid. Int J Heat Mass Transf 92:76-82

54. Oztop HF, Abu-Nada E (2008) Numerical study of natural convection in partially heated rectangular enclosures filled with nanofluids. Int J Heat Fluid Flow 29:1326-1336

55. Ghasemi B, Aminossadati SM, Raisi A (2011) Magnetic field effect on natural convection in a nanofluid-filled square enclosure. Int J Therm Sci 50:1748-1756

56. Hu Y, He Y, Qi C, Jiang B, Schlaberg HI (2014) Experimental and numerical study of natural convection in a square enclosure filled with nanofluid. Int J Heat Mass Transf 78:380-392

57. Krane RJ, Jessee J (1983) Some detailed field measurements for a natural convection flow in a vertical square enclosure. In: Proceedings of the 1st ASME-JSME thermal engineering joint conference, Hawaii, vol 1, pp 323-329

Publisher's Note Springer Nature remains neutral with regard to jurisdictional claims in published maps and institutional affiliations. 